ECONOMIC GROWTH CENTER

YALE UNIVERSITY

P.O. Box 208269

New Haven, CT 06520-8269

http://www.econ.yale.edu/ egcenter/

CENTER DISCUSSION PAPER NO. 957

\title{
The Basic Public Finance of Public-Private Partnerships
}

\author{
Eduardo Engel \\ Yale University and NBER
}

\author{
Ronald Fischer \\ Universidad de Chile
}

Alexander Galetovic

Universidad de Los Andes

July 2007

Revised February 2008

Notes: Center discussion papers are preliminary materials circulated to stimulate discussion and critical comments.

We thank Maham Mela for research assistance, and Hadi Esfahani, Antonio Estache, Aldo Gonzalez, James Hines, Mervyn Lewis, Guillermo Perry, John Shoven and participants at various conferences and workshops for insightful comments on an earlier version of this paper. We also thank the World Bank and Milenio (Chile) for financial support, and the Stanford Center for International Development for its hospitality. The views are our own and do not represent those of the World Bank. The views expressed herein are those of the author(s) and do not necessarily reflect the views of the National Bureau of Economic Research. Engel: eduardo.engel@yale.edu; Fischer:

rfischer@dii.uchile.cl; Galetovic: agaletovic@uandes.cl.

This paper can be downloaded without charge from the Social Science Research Network electronic library at: http://ssrn.com/abstract=1001758

An index to papers in the Economic Growth Center Discussion Paper Series is located at: http://www.econ.yale.edu/ egcenter/research.htm 


\title{
The Basic Public Finance of Public-Private Partnerships
}

\author{
Eduardo Engel Ronald Fischer Alexander Galetovic \\ Yale and NBER U. de Chile U. de los Andes
}

This version: February 3, $2008^{1}$

\begin{abstract}
Public-private partnerships (PPPs) cannot be justified because they free public funds. When PPPs are justified on efficiency grounds, the contract that optimally balances demand risk, user-fee distortions and the opportunity cost of public funds, features a minimum revenue guarantee and a revenue cap. However, observed revenue guarantees and revenue sharing arrangements differ from those suggested by the optimal contract. Also, this contract can be implemented via a competitive auction with realistic informational requirements. Finally, the allocation of risk under the optimal contract suggests that PPPs are closer to public provision than to privatization.

Keywords: Bundling, cost of public funds, Demsetz auction, minimum revenue guarantees, privatization, revenue and profit caps, scope of government, subsidies.

JEL classification: H21, H54, L51, R42.

\footnotetext{
${ }^{1}$ Engel: Department of Economics, Yale University, 28 Hillhouse Ave., New Haven, CT 06511. Fischer: Center for Applied Economics (CEA), Department of Industrial Engineering, University of Chile, Av. República 701, Santiago, Chile. Galetovic: Facultad de Ciencias Económicas y Empresariales, Universidad de Los Andes, Av. San Carlos de Apoquindo 2200, Santiago, Chile. E-mails: eduardo.engel@yale.edu, rfischer@di.uchile.cl, agaletovic@uandes.cl. We thank Maham Mela for research assistance, and Raj Chetty, Peter Diamond, Hadi Esfahani, Antonio Estache, John Friedman, Aldo González, James Hines, Mervyn Lewis, Guillermo Perry, Eduardo Saavedra, John Shoven, and participants at various conferences and workshops for insightful comments on an earlier version of this paper. We also thank the World Bank and the Instituto Milenio de Sistemas Complejos en Ingeniería (Chile) for financial support, and the Stanford Center for International Development for its hospitality. The views are our own and do not represent those of the World Bank.
} 


\section{Introduction and motivation}

The use of Public-Private Partnerships (PPPs) to replace the public provision of infrastructure services has become common in recent years. ${ }^{2}$ Projects that require large up-front investments, such as highways, water and sewerage, bridges, seaports and airports, hospitals, jails and schools are often provided via PPPs. ${ }^{3}$ The main characteristic of a PPP, compared with the traditional approach to the provision of infrastructure, is that it bundles investment and service provision in a single long term contract. For the duration of the contract, which can be as long as twenty or thirty years, the concessionaire will manage and control the assets, usually in exchange for user fees, which are its compensation for the investment and other costs. ${ }^{4}$ At the end of the franchise, the project reverts to government ownership. ${ }^{5}$

As the economics of PPPs is still imperfectly understood, practice has run ahead of theory. Some practitioners and governments claim that PPPs relieve strained budgets and release public funds, ${ }^{6}$ while others suggest that PPPs are appealing because finance, investment and management is delegated to private firms, which are more efficient. Despite these seemingly reasonable arguments, the experience with PPPs has been mixed. Whereas in some cases previous expectations are met, in many more cases contracts are renegotiated in favor of the concessionaire, or conversely, are subject to regulatory takings. Often deadlines are not met, or the project requires substantial subsidies to be finished

\footnotetext{
${ }^{2}$ The surge in PPPs is reflected in the financial press. For example, articles in the Financial Times mentioning this concept increased twenty-fold over the last decade, from 50 in 1995 to 1,153 in 2004. In Britain about $14 \%$ of public investment is now done under the so-called Private Finance Initiative (Bennet and Iossa, 2006).

${ }^{3}$ The case of PPPs in the transportation sector is particularly compelling. Congestion costs in the top U.S. metro areas have grown steadily, reaching $\$ 63.1$ billion in $2003,60 \%$ higher (in real terms) than a decade earlier (Schrank and Lomax, 2005). This fact, combined with budgetary problems, and technological improvements in toll collection, has led more than 20 U.S. states to pass legislation allowing the operation of public-private partnerships to build, finance and operate toll-roads, bridges and tunnels ("Paying on the Highway to Get Out of First Gear." New York Times, April 28, 2005). Recent examples of PPP contracts in the U.S. transport sector include the Dulles Greenway, the Southbay Expressway, the Chicago Skyway, the Indiana Toll Road and the Pocahontas Parkway.

${ }^{4}$ Compensations may also include up front subsidies or shadow tolls, paid by the government for the use of the project.

${ }^{5}$ There are several definitions for "Public-Private Partnership". In this paper we take it to mean an infrastructure project such that (i) assets are controlled by a private firm for a (possibly infinite) term; (ii) during the duration of the contract, the firm is the residual claimant, while the government is the residual claimant at the end of the concession. However, these claims are ambiguous due to contract incompleteness; and (iii) there is considerable amount of public planning in the design of the project. We use the term "concession" as synonymous to PPP.

6 "The boom is good news for governments with overstretched public finances: many local and national authorities have found themselves sitting on toll roads, ports and airports that they can sell for billions of dollars to fund other public services." Financial Times, July 5, 2007.
} 
(Guasch, 2004). ${ }^{7}$ The reason seems to be that the profitability of PPP projects is subject to large exogenous demand uncertainty, which is often not considered properly when designing the contracts. This explains why renegotiations take place when demand is lower than expected, as well as the array of risk sharing agreements that are observed.

The purpose of this paper is to contribute to the normative analysis of PPPs by answering two questions. First, what is the structure of the optimal risk-sharing contract between government and concessionaire when there is substantial exogenous demand risk? Second, what is the impact of PPP's on the the government budget? In order to answer these questions we use a stylized model in which the government contracts a risk averse firm to build, operate and maintain an infrastructure project. ${ }^{8}$ The investment is upfront, there are no further costs and the demand for the project is perfectly inelastic, exogenous and stochastic. ${ }^{9}$ The concessionaire receives a combination of state dependent user fees and subsidies (i.e., direct transfers) as compensation for its efforts. Thus our model encompasses the range from traditional provision of infrastructure, in which the government pays for the project and the firm collects no user fees, to the case of full concession, in which the only repayment is through user fees. ${ }^{10}$

We assume that there is a cost of raising public funds, so that a dollar in government revenues costs more than a dollar to society. This leads directly to our first result, namely that PPPs do not release public funds, contrary to the first argument for this contractual arrangement. The reason is that the user fee revenues that are used to repay the franchise holder could have been received by the government instead and used to reduce distortionary taxes, so there is no net gain to the government in discounted value. That is, under a PPP the government saves on investments early on in the relationship, yet these savings are offset one-for-one by ceding revenue flows to the private sector. ${ }^{11}$ Hence the distor-

\footnotetext{
${ }^{7}$ This does not mean that the traditional approach to infrastructure provision, with the government contracting a private firm to build the project, would have done better. For an early evaluation of infrastructure PPPs, see Economic Planning Advisory Commission (EPAC) (1995), Final Report of the Private Infrastructure Task Force, Australian Government Publishing Service, Canberra. For more recent evaluations, see Engel et al. (2003) and Grimsey and Lewis (2007).

${ }^{8}$ As in principal-agent models, the less risk averse party - in our case the government- is assumed to be risk neutral. Assuming a risk averse firm is a shortcut for agency problems preventing risk diversification, see Appendix D in the working paper version of Engel et al. (2001) for a model along these lines. Martimort and Pouyet (2006) also assume a risk-averse concessionaire. Finally, note that similar results are obtained by assuming a risk neutral firm subject to expropriation risk, see Engel and Fischer (2008).

${ }^{9}$ Later we relax these restrictions on costs and demand.

${ }^{10}$ Given that demand is inelastic, in any given state the total revenue derived from user fees depends only on the length of the franchise in that state.

${ }^{11}$ If the government is credit constrained, in the sense that it expects that the total cost of raising public funds will be lower in the future, our argument fails. However this expectation should be credible and not wishful thinking. In many countries, the government can be periodically credit constrained and our argument continues to hold.
} 
tionary cost of taxation is not a rationale for the use of PPPs.

Having shown that private financing cannot by itself justify a PPP raises the question of whether there exist other reasons to use PPPs. Hart (2003) argued that the main characteristic of these contractual arrangements is that they bundle investment expenditure with life-cycle operation costs. ${ }^{12}$ A PPP achieves the most efficient mix of these costs and is therefore superior to conventional methods of infrastructure provision when cost cutting increases social welfare. In some environments cost cutting leads to lower service quality, and conventional provision should be preferred.

In this paper we focus on the financial aspect of bundling in PPPs. In particular, we observe that the firm can be compensated with user fees, and that these represent a large fraction of their revenues. If the government is inefficient in the transfer of subsidies to the concessionaire (because the private sector pays lower overhead, is less corrupt, or for another reason), reducing subsidies and replacing them with revenues from user fees increases productive efficiency. The reason is that PPPs avoid either intermediation by the government (if user fees are incorporated into the government budget) or the increase in the distortion in the economy caused by raising taxes in other sectors (if there are no user fees). This argument is not sufficient for favoring PPPs, since it is possible that incentives to reduce costs by lowering service quality militate against PPPs. However, we show that, provided that PPPs are preferred due to Hart's arguments, the optimal risk-sharing contract has a common structure.

Given our assumption that there is a cost of the subsidy in addition to the distortive effect of collecting government revenue, the planner prefers user fees over subsidies as compensation. However, the allocation of user fees and revenues across the different states of nature is not obvious. Too see this, consider first the case in which there is no cost of a transfer to the firm. ${ }^{13}$ The optimal contract eliminates risk by returning exactly the investment costs to the firm, by any combination of user fees and transfers that add up to investment costs. If demand is high in a given state, this can be achieved by providing the firm with user revenues until its costs are collected. In low demand states, a subsidy makes up for the shortfall in revenues.

If subsidies are costly, it is still feasible to provide full insurance in all states. The planner can design a contract of infinite length in low demand states, in order to provide the smallest subsidy that makes up the shortfall to investment costs, and maintain the previous contract length in high demand states. This is not, however, the optimal contract. The reason is that the planner can improve on this contract by trading off increased risk for the

\footnotetext{
${ }^{12}$ See also Bennet and Iossa (2006), Bentz et al. (2005) and Martimort and Pouyet (2006).

${ }^{13}$ In this example we assume there are no maintenance costs.
} 
franchise holder against lower subsidies. It can lengthen the term of the franchise in high demand states, so that user fee revenues exceed investment costs, thus lowering the need for subsidies in low demand states. This contract is better because user fees foregone by the planner in high demand states are less valuable at the margin than subsidies required in low demand states: this wedge drives our results. This strategy tends to increase social welfare but becomes increasingly expensive as the firm is forced to bear more risk. We characterize the optimal contract under these circumstances.

In the optimal contract, all high demand states face a common revenue cap that is higher than investment costs, and the contract length is finite. Low demand states are characterized by user fee revenues below a bound, even with an infinite contract length. Subsidies are then used to raise the compensation in those states to the common lower bound (i.e., they represent a minimum revenue guarantee). In states with intermediate demand, with insufficient revenues to attain the revenue cap, but with revenues above the guaranteed lower bound, the franchise term is of infinite length, but the firm does not receive a subsidy. The reason is that the marginal cost to the firm of increased risk lies within the wedge in marginal social costs.

There are two special cases where the optimal contract provides full insurance. When all states have high demand, the franchise length depends on the state but is finite and user fees recover investment costs in all states. On the other hand, when all states are low demand and user fee revenues never recover investment costs, the franchise length is infinite in all states and a subsidy covers the difference between user fee revenues and investment costs. The reason for providing full insurance in both cases is that the marginal social cost of compensation does not vary across states, so there is no marginal cost wedge to exploit. These characteristics of the optimal contract is extended to the case when demand is price responsive and when there are operational and maintenance costs.

Even though such a contract would appear to be difficult to implement, we show that it can be attained in a competitive auction. The government announces the probability density of the different states, and the marginal costs of government funds and of transfers. Firms bid both a minimum revenue guarantee and a revenue cap. The government scores the bids according to the planner's objective function and chooses the one with the lowest score. Assuming firms with identical costs and competition, the auction reproduces the optimal revenues caps and guarantees. The auction does not require that the government know investment costs or the degree of risk aversion of firms.

Moral hazard does not play a significant role for some important types of infrastructure, such as highways, where service and infrastructure quality can be verified at a low cost by independent parties. In other cases however, such as airport and seaports, jails and 
hospital services, unenforceable effort by the concessionaire can play an important role. For this reason, we extend the model to the case of moral hazard. We assume that effort during the investment stage shifts the probability distribution towards higher realizations of demand. Hence the optimal contract must provide incentives to effort. This implies that this contract cannot have flat compensation regions as in the case of no moral hazard. The optimal contract will still have demand levels defining high and low demand states, but the compensation in these states combines the desire to reduce risk with the need to provide incentives, and is therefore state-contingent, i.e., there is a partial subsidy in bad states and a progressive tax in good states.

The optimal demand risk-sharing contract we derive in this paper has implications for the ongoing debate on privatizations and PPPs. ${ }^{14}$ The literature points out that bundling has several attributes which are typically associated to privatization. Thus in a PPP the concessionaire owns assets (Hart, 2003); ${ }^{15}$ retains control over how to produce the service and may unilaterally implement any cost-saving innovation (Bennet and Iossa, 2006); and directly collects user fees (Grout and Stevens, 2003). ${ }^{16}$ However, another hallmark of privatization is that demand risk is transferred to the firm. ${ }^{17}$ In this paper we show that if demand risk is allocated optimally, the allocation of revenue in PPPs, in present-value terms, is often similar to that under conventional provision of infrastructure. Most, or even all, risk is borne by the government and the concessionaire recovers the upfront investment in most states. Moreover, in the optimal contract the concessionaire should receive no compensation after the end of the concession, once the asset is transferred to the government. By contrast, under privatization, assets and cash flows are transferred forever to a private firm in exchange for a one time payment. This means that the link between the project and the public budget is permanently severed. Under a PPP this link continues to exist, even when the compensation to the concessionaire is derived solely from user fees.

\footnotetext{
${ }^{14}$ See, for example, Daniels and Trebilcock (1996, 2000), Gerrard (2001), Savas (2000), and Starr (1988)

${ }^{15}$ Though usually it needs authorization to sell assets that are comprised in the concession.

${ }^{16}$ In a different vein, Besley and Ghatak (2001) show that when contracts are incomplete, transferring the ownership of the assets needed to produce a public good to a private party is efficient, when that party values the benefits created by the public good relatively more.

${ }^{17}$ Eurostat, the Statistical Office of the European Communities, focuses on this feature when deciding whether a PPP-asset should be classified as governmental or not: "Eurostat recommends that the assets involved in a public-private partnership should be classified as non-government assets, and therefore recorded off balance sheet for government, if both of the following conditions are met: (1) the private partner bears the construction risk, and (2) the private partner bears at least one of either availability or demand risk." Eurostat Press Office, February 11, 2004.
} 


\section{Relation to the Literature}

There is a growing literature on PPPs related to this paper. ${ }^{18}$ Risk sharing between the government and the concessionaire has been always a concern among practitioners and policy makers. The standard prescription is that each risk should be allocated to the party best able to manage it. Irwin (2007, p. 14) is more precise: each risk should be allocated to maximize project value, taking account of moral hazard, adverse selection and risk-bearing preferences. ${ }^{19}$ Martimort and Pouyet (2006) study this problem in a moral hazard model where effort during investment affects both the quality of the infrastructure and its operating cost. Bentz et al. (2005), on the other hand, study a model with moral hazard in building and adverse selection in operation.

Our paper, by contrast, studies the implications of the optimal allocation of demand risk, when subsidy finance is less efficient than user-fee finance. Even though we consider the extension to the case with moral hazard, our main findings are best illustrated without this assumption. We show that intertemporal and not period-by-period risk matters in the case of PPPs. This implies that variable, state-contingent concession lengths are a key component of the optimal risk-sharing contract. Moreover, the explicit modeling of the intertemporal nature of PPPs shows that there is no fundamental difference between revenue guarantees and subsidies, since guarantees are analogous to state-contingent subsidies. In addition, we provide a rigorous foundation for minimum revenue guarantees and revenue caps and show that the optimal guarantees and caps bear no relation to observed guarantees and revenue sharing agreements.

Our results follow from the assumption that a large risk-neutral government, able to spread risk, contracts with a risk-averse firm to undertake a "small" project. In the context of PPPs, some authors find this assumption entirely plausible and probably correct (see, for example, Dewatripont and Legros [2005, pp. 133 and 134] and Hart [2003, p. C75]). Others are skeptical, and point out that private firms can use the capital market to diversify risks at least as well as the government. ${ }^{20}$ We do not claim to have solved this controversy. But we point out that the case for PPPs is very weak if private firms are more efficient and better at diversifying risks, because then privatization dominates PPPs. Moreover, it is a well known fact that private firms routinely demand minimum revenue guarantees because they deem

\footnotetext{
${ }^{18}$ See Grimsey and Lewis (2004) for a survey, history and experience, and Grimsey and Lewis (2005) for a collection of articles on PPPs. Vaillancourt-Rosenau (2000) and Akintoye et al. (2003) include useful collections of essays.

${ }^{19}$ See also the discussion in Dewatripont and Legros (2005).

${ }^{20}$ See, for example, Hemmings [2006 pp 12 and 13] and Klein (1997). For a discussion of the controversy in economics see Brealey et al. (1997)
} 
demand risk in PPPs excessive. ${ }^{21}$

This paper is also related to the literature on franchise bidding pioneered by Chadwick (1859) and Demsetz (1968), according to which competition for a monopoly infrastructure project will replicate the competitive outcome (see Stigler [1968], Posner [1972], Riordan and Sappington [1987], Spulber [1989, ch. 9], Laffont and Tirole [1993, chs. 7 and 8], Harstad and Crew [1999] and Engel et al. [2001] for papers within this tradition, and Williamson [1976, 1985] for a criticism). We contribute to this literature by considering cases where projects are not self-financing and government subsidies are necessary to make them feasible. We also show that in that case the optimal risk-sharing contract can be implemented with a two-threshold auction with realistic informational requirements.

Finally, in Engel et al. (2001), we studied the optimal private provision of infrastructure projects by solving a Ramsey problem with variable concession lengths. In that paper we assumed a "self-financing constraint," which ruled out government transfers to the concessionaire. In the present paper, demand-contingent government subsidies play a central role, thus providing a framework to study the public finance of PPPs.

The remainder of the paper is organized as follows. The model and the basic irrelevance result when there is no difference between government and private provisions is presented in section 2. In section 3 we derive the optimal risk-sharing contract when subsidy spending is inefficient. Section 4 shows how the optimal contract can be implemented with an auction, and section 5 presents the extensions. Section 6 concludes and is followed by several appendices.

\section{Benchmark model and irrelevance result}

A risk-neutral benevolent social planner must hire a concessionaire to finance, build and operate an infrastructure project with exogenous technical characteristics. There are no maintenance nor operation costs, ${ }^{22}$ the up-front investment does not depreciate, and the concessionaire is selected among many firms that can build the project at cost $I>0 .{ }^{23}$ All

\footnotetext{
${ }^{21} \mathrm{~A}$ similar concern possibly underlies the recent move in Europe away from shadow toll contracts towards availability payments.

${ }^{22}$ This assumption is relaxed in section 5 . In any case, there are two reasons why ignoring maintenance and operations costs is not a serious limitation. First, for many infrastructure projects, upfront costs are much larger than maintenance and operation costs (consider the examples of highways, dams, sport stadiums and rail lines). Secondly, if maintenance and operations costs are proportional to demand for the project, which is a good approximation in the case of highways and rail lines, then the case with maintenance and operations costs is a trivial extension.

${ }^{23}$ That is, we ignore construction cost uncertainty and focus instead on demand uncertainty, which is considerably larger for many PPP projects.
} 
firms are identical, risk-averse expected utility maximizers, with preferences represented by the strictly concave utility function $u$ (see footnote 8 ).

We assume that the project is socially profitable and that a PPP yields a higher social surplus than conventional unbundled provision (appendices A and B spell out conditions for this to be the case).

Demand uncertainty is summarized by a probability density over the present value of user fee revenue that the infrastructure can generate over its entire lifetime, $f(v)$, with c.d.f. $F(v)$. This density is common knowledge to firms and the planner, and is bounded from below by $v_{\min }$ and from above by $v_{\max }$. Also, for simplicity we assume that $v$ equals the discounted private willingness to pay for the project's services. ${ }^{24}$

\subsection{Planner's problem}

Let $\operatorname{PS}(v)$ denote producer surplus in state $v, \operatorname{CS}(v)$ denote consumer surplus in state $v$ and $\alpha \in[0,1]$ be the weight that the planner gives to producer surplus in the social welfare function. ${ }^{25}$ The planner's objective is to maximize ${ }^{26,27}$

$$
\int[\mathrm{CS}(v)+\alpha \operatorname{PS}(v)] f(v) d v,
$$

subject to the concessionaire's participation constraint

$$
\int u(\operatorname{PS}(v)) f(v) d v \geq u(0),
$$

where $u(0)$ is the concessionaire's outside option. ${ }^{28}$

To maximize (1), the planner chooses how much user fee revenue and subsidy the concessionaire should receive in each state $v$. Denote by $R(v)$ the present value of user fee revenue collected by the concessionaire in state $v$, and by $S(v)$ the present value of the

\footnotetext{
${ }^{24}$ In Appendix A we show that this and other simplifications do not affect the structure of the optimal PPP contract.

${ }^{25}$ In many countries foreign firms are important investors in PPPs, which implies $\alpha<1$.

${ }^{26}$ This objective function assumes that the income of users is uncorrelated with the benefit of using the project, so that if users spend a small fraction of their incomes on the services of the project they will value the benefits produced by the project as if they were risk neutral. See Arrow and Lind (1970).

${ }^{27}$ The planner cares about firms' profits not per se but because these constitute a source of income for firms' owners. This, combined with the assumption that the planner can redistribute income among consumers at no social cost and that each project is relatively small compared to the size of the economy, explains why producer surplus, and not the expected utility of the firm's profits, enters the planner's objective function.

${ }^{28}$ Since the concave utility function $u(\cdot)$ captures the firm's risk premium, we may assume the same probability density for the planner's objective function and the concessionaire's participation constraint.
} 
subsidy it receives. Hence

$$
\operatorname{PS}(v)=R(v)+S(v)-I
$$

Note that by "subsidy" we mean any cash transfer from the government to the private concessionaire. It may be the up-front payment made by the government with conventional unbundled provision (in which case $S(v)$ is the same for all $v$ ), but it could also be a cash transfer made over time, contingent on $v$, to supplement revenue from the project under a Build-Operate-and-Transfer (BOT) contract (a so-called 'minimum revenue guarantee').

Since the concessionaire receives $R(v)$ in state $v$, the government receives $v-R(v)$ and we have $0 \leq R(v) \leq v$. If the term of the concession is finite and $v-R(v)>0$, these funds are used to reduce distortionary taxation elsewhere in the economy. Moreover, assuming that willingness to pay is positive at all points in time, we have that $R(v)=v$ only when the concession lasts forever.

Let $\mathscr{E}$ be an externality generated by the project and $1+\lambda>1$ the cost of public funds. Then

$$
\begin{aligned}
\operatorname{CS}(v) & =[v-R(v)-(1+\lambda) S(v)]+\mathscr{E}+\lambda[v-R(v)] \\
& =(1+\lambda)[v-R(v)-S(v)]+\mathscr{E}
\end{aligned}
$$

The first term in the r.h.s. of (3a), $v-R(v)-(1+\lambda) S(v)$, is the difference between users' willingness to pay in state $v$ and the total amount transferred to the concessionaire, where the cost of the subsidy is increased by the tax distortion required to finance it. The term $v-R(v)$ is total revenue collected by the government (after the end of the concession), so the second term in the r.h.s. of (3a) corresponds to the reduction in distortionary taxes due to this increased revenue.

Substituting (2) and (3b) in (1) shows that maximizing the planner's objective function (1) is equivalent to maximizing

$$
-(1+\lambda-\alpha) \int[R(\nu)+S(\nu)] f(\nu) d \nu
$$

and therefore to minimizing

$$
\int[R(v)+S(v)] f(v) d v
$$

Where we have dropped $\mathscr{E}, \alpha I$ and $(1+\lambda) v$ from the objective function because they do not depend on the planner's choice variables, $R$ and $S$, and where we have used that $1+\lambda>1 \geq$ 
$\alpha$. The planner's program can be rewritten as ${ }^{29}$

$$
\begin{gathered}
\min _{\{R(v), S(v)\}} \int[R(v)+S(v)] f(v) d v . \\
\text { s.t. } \quad \int u(R(v)+S(v)-I) f(v) d v \geq u(0), \\
0 \leq R(v) \leq v \\
S(v) \geq 0
\end{gathered}
$$

\subsection{Irrelevance result}

It has been claimed that a PPP is desirable because it relieves the public budget by substituting private finance for distortionary tax finance. ${ }^{30}$ Does this argument make the case for PPPs?

It follows from the objective function (4) that the per-dollar cost of paying the concessionaire with user fee revenues or subsidies is the same. Thus, social welfare only depends on total transfers $\mathscr{T}(v)=R(v)+S(v)$ to the concessionaire, not on the partition between subsidies and user fee revenue. This is the fundamental insight behind the following result:

Proposition 1 (Irrelevance of the cost-of-funds argument) Any combination of user fee and subsidy schedules that satisfies constraints $(5 c)$ and $(5 d)$ and such that $\mathscr{T}(v)=I$ for all $v$ solves the planner's program (5a)-(5d).

Proof See Appendix D.1.

What is the economics of this result? The standard reasoning in favor of PPPs points out that subsidies are an expensive source of finance, because they are financed with distortionary taxes. Yet the multiplicity of optimal subsidy-sales revenue combinations indicates that distortionary taxation $(\lambda>0)$ is not sufficient to prefer private provision. One solution is $R(v) \equiv 0$ and $S(v) \equiv I$. Another solution is that the concessionaire invests $I$, collects userfee revenues equal to $I$ in present value, and no subsidies are paid. ${ }^{31}$ In addition, there is a continuum of combinations where the government provides a partial subsidy.

\footnotetext{
${ }^{29}$ In Appendix A we consider several additional variables mentioned in the literature that may influence the choice in favor or against a PPP. In all cases these additional variables are independent of the planner's choice functions, $R$ and $S$. Consequently, if the planner goes for a PPP, her objective function remains similar to (4). In Appendix A we also show that it is straightforward to model exogenous restrictions on term length, an imperfect ability to appropriate consumer surplus using user fees, and so on. In all cases the additional constraints or variables affect the particular solution to program (5a)-(5d), but not its structure.

${ }^{30} \mathrm{An}$ even bolder claim is that $I$ in public funds are permanently liberated with a PPP. But setting up the problem in present value terms immediately exposes this fallacy-the concessionaire must recover its investment by receiving future payments.

${ }^{31}$ This is only possible if $v_{\min } \geq I$, for otherwise the project cannot be financed with user fees in all states.
} 
The intuition for this result is that if the user fee revenue collected by the concessionaire increases by $\$ 1$, the government has to levy $\$ 1$ in additional taxes to replace this transfer, which costs society $1+\lambda$. This is the same cost that society bears when paying $\$ 1$ in additional subsidies. Hence, at the margin the opportunity cost of user fee revenue or subsidizing the concessionaire is exactly the same. The rich set of optimal combinations of state-contingent subsidies and concession terms reflects that user fees and subsidies are perfect substitutes in the planner's objective function.

A similar argument shows that the planner will satisfy the concessionaire's participation constraint with equality. An additional dollar in the concessionaires pocket increases social welfare by $\alpha$, but costs $1+\lambda$ to users. Since $1+\lambda>\alpha$, the planner chooses not to provide rents to the concessionaire. Finally, note that the optimal contract provides full insurance to the concessionaire.

\section{Application: Evaluating shadow fees and availability payments}

In several industrialized countries PPPs are fully financed with subsidies. However, instead of paying for the infrastructure up-front, the concessionaire is compensated with so-called "shadow fees," that is, per-user fees paid directly by the government for a fixed period of $T$ years. For example, Britain highway concessionaires are paid a shadow toll for each car on the highway. Proposition 1 suggests that these contracts are suboptimal because the concessionaire is forced to bear risk.

If, on the other hand, the concessionaire is paid a so-called availability payment-a yearly sum independent of the realization of demand, but conditional on delivering the agreed service quality -, the concessionaire bears no risk, and the contract is optimal if the concessionaire receives no rents. ${ }^{32}$ Thus, Proposition 1 provides an argument against fixed term contracts with shadow fees, and in favor of availability contracts. ${ }^{33}$

Corollary 1 When no user fees can be charged (usually due to political constraints), $S(v)=I$ for all states $v$ characterizes the unique optimal contract. Hence shadow fees which make payments contingent on the use of the infrastructure for a fixed and finite term $T$ are not optimal. By contrast, availability contracts that leave no rents for the firm are optimal.

\footnotetext{
${ }^{32}$ This result extends to the case where yearly payments by the government also include operational costs incurred by the firm to satisfy demand. What is central for the result to hold is the absence of a link between demand realizations and the recovery of the upfront investment.

${ }^{33}$ Shadow fees may be more attractive when the firm can exert costly effort to influence demand. See Section 5.2
} 


\section{Optimal contract with inefficient subsidies}

The irrelevance result implies that the case for PPPs cannot rest on the claim that they relieve strained budgets. When are PPPs warranted? As mentioned in the introduction, one justification of PPPs is that bundling may enhance productive efficiency (see section 3.6). An additional advantage of PPPs is that they reduce the sums flowing through the public budget, reducing the inefficiencies associated with subsidy transfers. In this section we derive the optimal contract when subsidy financing is less efficient than user-fee financing.

\subsection{Modeling the inefficiency of subsidy financing}

To model inefficient subsidy financing, we assume that achieving $\$ 1$ of useful spending costs $\$ 1$ if financed with user fees collected directly by the concessionaire, but $1+\zeta>1$ dollars if financed with a subsidy. If subsidies are monetary transfers from the government to the concessionaire, then $\zeta>0$ means that some of the resources are wasted in the process, perhaps because of agency problems faced by the budgetary authority when monitoring the government agency in charge of the resource transfer. More generally, in Appendix C we provide a microfoundation for the value of $\zeta$. We show that if the government runs an optimal fiscal policy, then the shadow cost of subsidizing the PPP with one additional dollar can be assessed from two different, but equivalent, perspectives. On the one hand, one could increase the aggregate tax burden by $1+\zeta$, which would cost society $(1+\lambda)(1+\zeta)$ dollars. On the other hand, the government could achieve the same transfer by reducing current spending by $1+\zeta$ dollars. If fiscal policy is optimal, the opportunity cost is equal to the return of the government's marginal project, which equals $(1+\lambda)(1+\zeta) .^{34}$

Formally, introducing $\zeta$ implies that the term $(1+\lambda) S(\nu)$ in (3a) must be replaced by $(1+$ $\lambda)(1+\zeta) S(\nu)$ - the inefficient subsidy transfer increases the magnitude of the tax distortion. The planner's program now is

$$
\begin{gathered}
\min _{\{R(\nu), S(v)\}} \int\{(1+\lambda-\alpha) R(\nu)+[(1+\lambda)(1+\zeta)-\alpha] S(\nu)\} f(\nu) d \nu . \\
\text { s.t. } \int u(R(\nu)+S(\nu)-I) f(\nu) d v \geq u(0), \\
0 \leq R(v) \leq v \\
S(\nu) \geq 0 .
\end{gathered}
$$

It is apparent from (6a) that if $\zeta>0$, user fees are a more efficientmeans of compensat-

\footnotetext{
${ }^{34}$ As discussed in Section 5.3, a value of $\zeta>0$ can be interpreted as temporary credit constraints faced by the government.
} 
ing the concessionaire. The cost to society of one dollar in user fees is $1+\lambda-\alpha$, while a subsidy costs $(1+\lambda)(1+\zeta)-\alpha$. Of course, $\zeta>0$ is not a sufficient argument against subsidizing projects, for the project's social value may exceed $I$, and user fee revenue may be insufficient to compensate the concessionaire in low demand states. But, as we will see next, $\zeta>0$ determines the structure of the optimal risk-sharing contract.

\subsection{Optimal risk-sharing contract: overview}

The tradeoff faced by the planner when $\zeta>0$ is the following: On the one hand, she would like to utilize user fee revenues as far as possible to compensate the concessionaire, in order to avoid paying subsidies. On the other hand, using only user fees may expose the concessionaire to excessive risk, and an efficient contract would insure against low demand states through subsidies.

Figure 1: Optimal contract, intermediate demand project

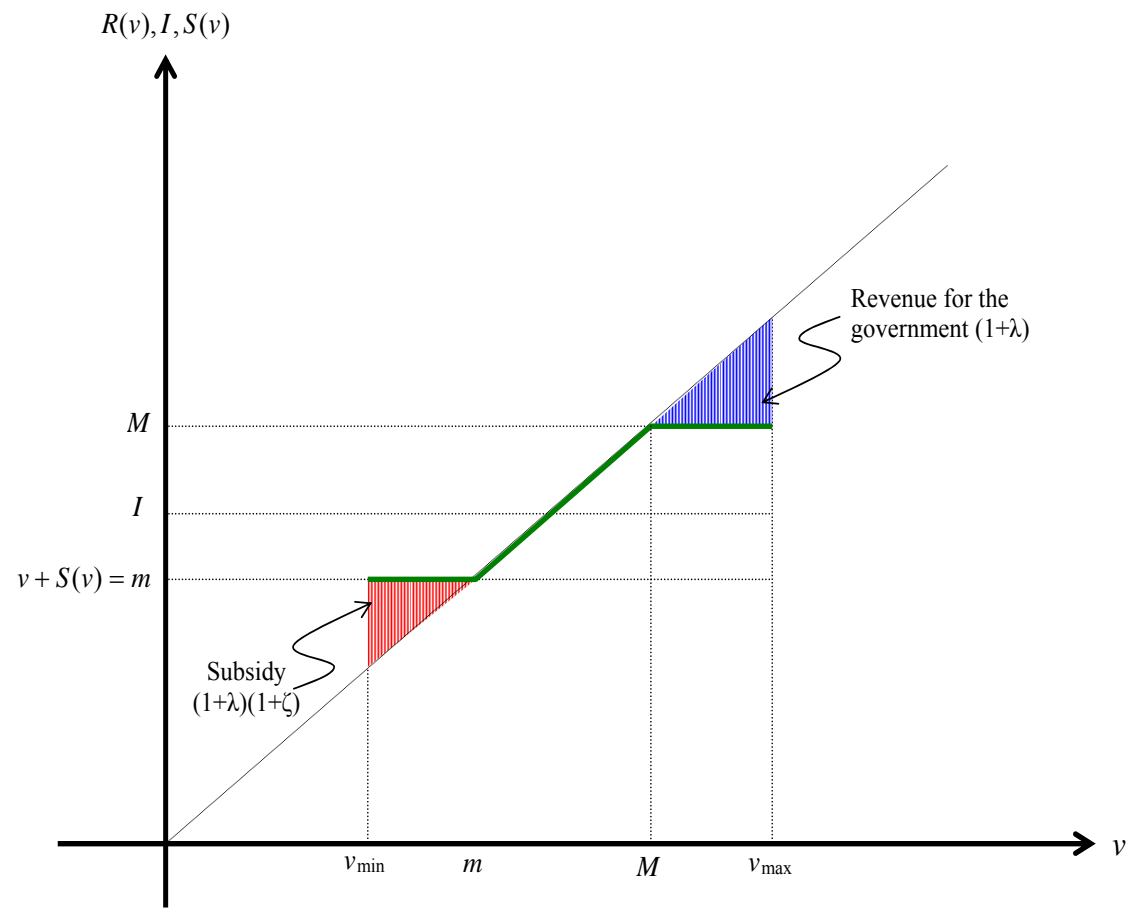

Figure 1 shows how the trade off is resolved optimally when $v_{\min }<I<v_{\max }$ (i.e., there are some states of demand in which user fee revenues is smaller than $I$ while there are 
others in which revenues are larger than $I$ ). The horizontal axis plots the support of $v$ while the vertical axis shows the total revenue received by the concessionaire in each state, $R(v)+S(v)$.

In the next section we show that the optimal contract is characterized by two thresholds, a minimum revenue guarantee $m$ and a revenue cap $M$. These thresholds, in turn, define three types of demand states. In low demand states $v<m, R(v)=v$ and $S(v)=m-v$. Hence the concession lasts forever and the concessionaire receives a subsidy to attain the guaranteed minimum revenue $m$. By contrast, in high demand states $v>M$ and $R(v)=M$. Thus the concession ends in finite time and the government gets $v-M$. The remaining cases, which we call intermediate demand states, are such that $m \leq v \leq M, R(v)=v$ and $S(\nu)=0$. In these states the concession lasts indefinitely, but no subsidies are paid.

\subsection{A taxonomy of demand states}

To derive the optimal contract, note that in state $v$ the planner will only resort to subsidies after exhausting user fees-otherwise, it could slightly reduce subsidy payments, which would save $(1+\lambda)(1+\zeta)-\alpha$; and increase $R(\nu)$, which would cost only $1+\lambda-\alpha$. Thus:

$$
S(v)>0 \Rightarrow R(v)=v
$$

or equivalently

$$
R(v)<v \Rightarrow S(v)=0
$$

Now let $\mu>0$ denote the multiplier of the concessionaire's participation constraint (6b). ${ }^{35}$ The FOC with respect to $R(v)$ for a state $v$ such that the term of the concession is finite leads to

$$
u^{\prime}(R(\nu)-I)=\frac{1+\lambda-\alpha}{\mu} .
$$

While the FOC with respect to $S(v)$ for a state where subsidies are paid leads to

$$
u^{\prime}(\nu+S(v)-I)=\frac{(1+\lambda)(1+\zeta)-\alpha}{\mu},
$$

where in both cases we have used that revenue financing dominates subsidy financing.

\footnotetext{
${ }^{35}$ Note that the participation constraint will hold with equality because $1+\lambda>\alpha$, hence $\mu>0$.
} 
Define $m$ and $M$ via

$$
\begin{aligned}
& u^{\prime}(m-I)=\frac{(1+\lambda)(1+\zeta)-\alpha}{\mu} \\
& u^{\prime}(M-I)=\frac{1+\lambda-\alpha}{\mu}
\end{aligned}
$$

and define $\bar{\zeta}$ via: ${ }^{36}$

$$
1+\bar{\zeta}=\frac{(1+\lambda)(1+\zeta)-\alpha}{1+\lambda-\alpha}
$$

Since $\zeta>0$ we have $m<M$ and

$$
u^{\prime}(m-I)=(1+\bar{\zeta}) u^{\prime}(M-I)
$$

It follows from (7) and (10) that in states with $v>M$ no subsidies are paid out and the concession lasts until the concessionaire collects $M$ in present value. The government, on the other hand, collects $v-M$ after the concession ends. Thus, in high demand states the concessionaire's revenue is capped by $M$ and the term of the concession is variable. ${ }^{37}$

Similarly, from (8) and (9) we have that a subsidy equal to $m-v$ is paid in states with $v<m$. Therefore, in low demand states the concession lasts indefinitely and the concessionaire receives a minimum revenue guarantee.

Finally, there is a third class of states of demand such that $m \leq v \leq M$. In these states the concession lasts indefinitely, for otherwise they would be high demand states. But no subsidies are paid out by the government, for otherwise they would be low demand states. It follows that $R(v)=v$ and $S(v)=0$ in this class.

We summarize this characterization in the following proposition:

Proposition 2 (A taxonomy of demand states) The optimal contract is characterized by a minimum revenue guarantee, $m$, and revenue cap, $M$, with $m<M$, as follows:

1. If $M<v$, the concessionaire collects $M$ in present discounted user fees while the government collects the remaining $v-M$. No subsidies are paid and the concession term is finite. These are high demand states.

2. If $m \leq v \leq M$, the concession lasts indefinitely and no subsidies are paid. Total revenues accrued to the concessionaire in present value equals $v$ and the government budget is unaffected by the concession. These are intermediate demand states.

\footnotetext{
${ }^{36}$ Note that $\bar{\zeta}=(1+\lambda) \zeta /(1+\lambda-\alpha)$. It follows that $\bar{\zeta}>0 \Longleftrightarrow \zeta>0$ and $\bar{\zeta}<0 \Longleftrightarrow \zeta<0$. Furthermore, $\zeta=\bar{\zeta}$ when $\alpha=0$.

${ }^{37}$ If demand grows at a the same rate in all demand states, this implies that higher values of $v$ correspond to shorter concession terms. This is not necessarily true with more general demand schedules.
} 


\section{If $v<m$, the concession lasts indefinitely and the government grants a subsidy of $m-v$} to the concessionaire. These are low demand states.

Let us comment on the economics of this taxonomy. In any state with a finite concession term, the social opportunity cost of the last dollar received by the concessionaire is $1+\lambda-\alpha$; this justifies equalizing the concessionaire's revenue across high demand states by fixing a revenue cap $M$. On the other hand, in any low demand state the last dollar paid to the concessionaire comes from a subsidy and costs society $(1+\lambda)(1+\zeta)-\alpha$. Again, this justifies equalizing revenue across low demand states at the minimum revenue guarantee $m<M$.

As can be seen from Figure 1, the difference between $1+\lambda-\alpha$ and $(1+\lambda)(1+\zeta)-\alpha$ introduces a wedge $M-m$ that leads to the emergence of intermediate demand states. To see the intuition, consider one such state, $\widetilde{v}$. It is straightforward to obtain the following inequalities

$$
\frac{1}{1+\bar{\zeta}}<\frac{u^{\prime}(\widetilde{v}-I)}{u^{\prime}(m-I)}<1<\frac{u^{\prime}(\widetilde{v}-I)}{u^{\prime}(M-I)}<1+\bar{\zeta} .
$$

These inequalities imply that the concessionaire's marginal utility evaluated at $\widetilde{v}-I$ is smaller than the marginal utility at $m$, but higher than the marginal utility at $M$. In other words, the shadow value of the last dollar received by the concessionaire in state $\widetilde{v}$ is too low to warrant a subsidy, as well as too high to warrant a revenue cap. Consequently, the concession lasts forever, but no subsidies are paid.

\subsection{A taxonomy of projects}

To complete the characterization of the optimal contract, we show how $m$ and $M$ are determined, which leads to a taxonomy of projects.

Consider first the case where user fees can finance the project in all demand states, that is, $v_{\min } \geq I$. The optimal contract sets $R(v)=M=I \leq v$ for all $v$, and the concessionaire receives full insurance-all states are high demand states when $v_{\min } \geq I .^{38}$ To see that this contract is optimal, note first that it is clearly feasible. Moreover, no contract can give less than $I$ on average to the concessionaire, for then the participation constraint would not hold; and had the concessionaire been forced to bear risk, he would have required more than $I$ on average.

\footnotetext{
${ }^{38}$ The formal proof is similar to that of Proposition 1. Also note that from $m<M$ it follows that no subsidies are paid out for all feasible values of $m$, and therefore this threshold is irrelevant to pin down the optimal contract.
} 
Consider next the case where user fees are never large enough pay for the project, that is, $v_{\max }<I$. Then $m=I$. For if $m>I$, all states are low demand, and the concessionaire's participation constraint holds with slack, which cannot be optimal. And if $m<I$, the concessionaire's participation constraint cannot be satisfied, because revenue in all demand states is smaller than $I$. It follows that $m=I$ while now $M$ is irrelevant. Thus, the optimal contract subsidizes the concessionaire in all demand states to ensure that total revenue is equal to the cost of the project.

We refer to a project with $v_{\min } \geq I$ as a high demand project, while one with $v_{\max }<I$ is a low demand project, and summarize these results in the following Proposition.

Proposition 3 (Optimal contract for high and low demand projects) The optimal contract for high and low demand projects specifies that $R(\nu)+S(v)=$ I for all $v$. Given demand realization $v$, the government collects $v-I$ in each state if the project is high demand, while it pays a subsidy of I - $v$ in each state if the project is low demand.

The economics of Proposition 3 should be apparent. The social cost of transferring an additional dollar to the concessionaire is $1+\lambda-\alpha$ in all states when a project is high demand, and full insurance immediately follows. In a low demand project the social cost of transferring an additional dollar to the concessionaire is higher (i.e., $(1+\lambda)(1+\zeta)-\alpha)$, but is also the same across states and therefore full insurance is optimal as well.

As we can see from Figure 1, the structure of the optimal contract is different for projects such that $v_{\min }<I \leq v_{\max }$, for a contract that gives full insurance to the concessionaire ( $m=M=I$ ) is no longer optimal. To see this, consider decreasing $m$ to $I-\Delta m$, and using the funds to increase $M$ to $I+\Delta M$. Lowering the minimum revenue guarantee frees up resources $F(I) \Delta m$ in expected value, and this can be used to finance an increase in $M$ of $F(I) \Delta m /(1-F(I)) .{ }^{39}$ Society is made better off in the process, since each dollar saved in guarantees is $1+\bar{\zeta}>1$ times more valuable than a dollar of foregone user fee revenue. Thus it follows from (6a) that the planner's objective function improves by $(1+\lambda) \zeta F(I) \Delta m$. Increased risk reduces the concessionaire's expected utility by an expression on the order of $(\Delta m)^{2}$. It follows that the optimal values of $m$ and $M$ satisfy $m<I<M$.

The following proposition characterizes the optimal values of both thresholds.

Proposition 4 (Optimal contract for intermediate demand projects) Consider a project with $v_{\min } \leq I<v_{\max }$ (intermediate demand project). Assume $u^{\prime}\left(v_{\min }-I\right)>(1+\bar{\zeta}) u^{\prime}\left(v_{\max }-I\right) .{ }^{40}$ Then the optimal contract is characterized by quantities $m$ and $M$, with $v_{\min }<m<I<M<$

\footnotetext{
${ }^{39}$ Since this is an intermediate demand project, $0<F(I)<1$.

${ }^{40}$ This condition ensures that $m>v_{\min }$ and $M<v_{\max }$, so that condition (12) below holds with equality. Two possibilities arise if $u^{\prime}\left(v_{\min }-I\right)<(1+\bar{\zeta}) u^{\prime}\left(\nu_{\max }-I\right)$. First, if $\int u(\nu-I) f(v) d v>u(0)$, the optimal contract
} 
$v_{\max }$, such that states with $v>M$ are high demand, states with $m \leq v \leq M$ are intermediate demand and states with $v<m$ are low demand. ${ }^{41}$ Also, $m$ and $M$ are determined from the concessionaire's participation constraint

$$
F(m) u(m-I)+\int_{m}^{M} u(v-I) f(v) d v+(1-F(M)) u(M-I)=u(0)
$$

and the condition

$$
u^{\prime}(m-I)=(1+\bar{\zeta}) u^{\prime}(M-I)
$$

Proof See Appendix D.2.

\subsection{Comparative statics}

Comparative statics for high and low demand projects are straightforward. When $I$ rises, the planner must transfer more revenue to the concessionaire. On the other hand, changes in $\bar{\zeta}$ or in the concessionaire's degree of risk aversion have no effect on the optimal contract.

By contrast, in an intermediate demand project both an increase in $\bar{\zeta}$ or a fall in the concessionaire's degree of risk aversion increases the wedge between the minimum revenue guarantee $m$ and the revenue cap $M$. Moreover, the risk premium demanded by a concessionaire with decreasing absolute risk aversion grows with $I$, but does not change if absolute risk aversion is constant. The following proposition formalizes these results:

Proposition 5 (Comparative statics) Denote by $m(\zeta, I)$ the minimum revenue guarantee, and by $M(\zeta, I)$ the revenue cap that characterize the optimal contract, both as a function of the inefficiency parameter $\zeta$ and the upfront investment $I$. Assume $(\zeta, I)$ is such that $\nu_{\min }<$ $m(\zeta, I)<M(\zeta, I)<v_{\max }$ and denote $\operatorname{CARA}(c) \equiv-u^{\prime \prime}(c) / u^{\prime}(c)$. Then:

(i) The risk borne by the concessionaire, as measured by the wedge $M-m$, increases with involves no subsidies $\left(m<v_{\min }\right)$ and $M$ is determined from

$$
\int_{v_{\min }}^{M} u(v-I) f(v) d v+(1-F(M)) u(M-I)=u(0) .
$$

By contrast, the optimal contract involves no revenue cap when $\int u(v-I) f(v) d v<u(0)$. In this case the minimum income guarantee is determined by

$$
F(m) u(m-I)+\int_{m}^{v_{\max }} u(v-I) f(v) d v=u(0) .
$$

\footnotetext{
${ }^{41}$ See Proposition 2 for the definition of high, intermediate and low demand states.
} 
the social cost of subsidies, $\zeta$. Furthermore,

$$
\frac{1+\lambda}{[(1+\lambda)(1+\zeta)-\alpha] \operatorname{CARA}(m-I)} \leq \frac{\partial M}{\partial \zeta}(\zeta, I)-\frac{\partial m}{\partial \zeta}(\zeta, I) \leq \frac{1+\lambda}{[(1+\lambda)(1+\zeta-\alpha] \operatorname{CARA}(M-I)} .
$$

(ii) The thresholds $m$ and $M$ are increasing in I and grow faster than I. Moreover, for a concessionaire with decreasing absolute risk aversion, the wedge between $M$ and $m$ increases with I, while it does not depend on I if the concessionaire has constant absolute risk aversion.

Proof See Appendix D.3.

\subsection{Applications}

Minimum income guarantees and revenue sharing Minimum income guarantees are routine in many types of PPPs. However, most real world contracts have a fixed term and therefore do not follow the prescriptions laid out in Proposition 4. These contracts would be closer to the optimal contract if their durations were longer in low demand states, when guarantees are paid out. Thus, real world contracts pay excessive guarantees in low demand states.

Real world profit and revenue sharing agreements also do not coincide with the revenue cap that characterizes the optimal contract. When governments impose profit sharing arrangements, they split revenues in excess of a given threshold with the concessionaire in fixed proportions. By contrast, Propositions 3 and 4 suggest assigning all the revenue in excess of a given threshold to the government-the windfall profits tax rate should be $100 \%$.

More generally, the rationale behind real-world guarantees and revenue sharing schemes is to reduce the risk borne by the concessionaire. By contrast, the rationale behind the optimal contract in Propositions 3 and 4 is to optimally trade off insurance on one hand, and the use of user fees and subsidies on the other. This is why the concession lasts indefinitely when subsidies (i.e., guarantees) are granted; the term is variable in high demand states; and the concessionaire's revenue in high demand states is higher than in low demand states.

When is a PPP warranted? Bundling, incentives and the optimal contract The structure of the optimal risk-sharing contract is largely determined by the desire to minimize subsidy finance. Bundling allows the planner to take cash flows off the public budget by substituting user fees for subsidies, thus increasing productive efficiency. Yet this is not 
always enough to make the case for a PPP. Whether a PPP is better than conventional unbundled provision also depends crucially on how bundling affects incentives.

The central observation was made by Hart (2003), who showed that bundling links investment spending with life-cycle operation costs. Hence, bundling stimulates noncontractible investments that cut operation costs. But cost cutting is not necessarily desirable, because it may come at the expense of lower service quality. Therefore, in his model, a PPP may be better if cost cutting is socially beneficial, but conventional provision probably carries the day if service quality cannot be well specified and cost cutting substantially deteriorates it. ${ }^{42}$

In different guises, this insight emerges in most comparisons of PPPs with conventional provision. Bennet and Iossa (2006) observe that PPPs also transfer ownership of the asset to the concessionaire and, in many cases, substitute output and performance measures for input specifications. With a PPP, then, the concessionaire retains some or all control rights over how to produce the service, and may unilaterally implement any cost-saving innovation. By contrast, with conventional provision the government retains the right to tell the concessionaire how to produce, and cost-reducing innovations can be implemented only after bilateral bargaining. ${ }^{43}$ Because of this, the case for a PPP again rests on the effect of cost-reducing innovations. If the main impact is to cut costs, with little or no effect on service quality and value, then a PPP is probably better. By contrast, if the main effect of innovations is to increase social surplus and perhaps to increase operation costs, conventional unbundled provision is better because only the government may care about social welfare.

Martimort and Pouyet (2006), in turn, analyze a moral hazard model where non-verifiable effort during construction increases quality and gross social surplus, but may either reduce or increase costs during operation. In line with incomplete contracting models, they show that a PPP beats conventional provision if and only if quality enhancements reduce operation costs.

Does the intertemporal incentive effects of bundling affect the structure of the optimal risk-sharing contract derived above? The answer is no. As we show in Appendix B, the costs and benefits affected by bundling are not functions of $R$ or $S$. For this reason, and as far as the planner's program is concerned, these variables are just like terms $\mathscr{E}$ or $\alpha I$

\footnotetext{
${ }^{42}$ See also Grout (1997).

${ }^{43}$ Typically, conventional unbundled provision assumes government ownership, while with a PPP the concessionaire owns the asset and has control rights over how to produce the service. Of course, ownership usually is limited, for example, authorization may be needed to sell assets or transfer the concession. Bennet and Iossa (2006) also study two rather unconventional structures: bundling with government ownership and unbundled provision with private ownership of assets and control rights over how to produce the service. We ignore such structures here.
} 
in the planner's problem. A neat separation thus emerges. On the one hand, incentives change when investment and life cycle costs are linked, and this affects whether a PPP is better than conventional provision. On the other hand, it does not affect the structure of the optimal risk-sharing contract conditional on choosing a PPP.

\section{Implementation}

The informational requirements needed to implement the optimal contract might seem formidable, but somewhat surprisingly, this is not the case. We show next how to implement the optimal contract with a competitive auction when the planner knows neither $I$ nor firms' risk aversion.

\subsection{High and low demand projects}

Consider first a high demand project. Then an auction where the bidding variable is the total present value of user fee revenues (PVR) collected by the concessionaire, $\beta$, implements the optimal contract. This follows from noting that rents will be dissipated in a competitive auction, so that $\beta$ will satisfy:

$$
\int u(\beta-I) f(v) d v=u(0) .
$$

Hence the winning bid will be $\beta=I$, which corresponds to the optimal contract derived in the preceding section. Denote by $T(v)$ the time it takes for user fee revenue accumulated in state $v$ to attain $I$. The concession term is shorter when demand is high, that is, when $T(v)$ is small. ${ }^{44}$ The concessionaire bears no risk because users pay him the same amount in all states of nature. ${ }^{45}$ Furthermore, the planner can implement the optimal contract using a PVR auction even if she does not know $I$, the density $f(\nu)$ or the concessionaire's degree of risk aversion. All the planner needs to know is that the project can finance itself in all states of demand, that is, that $v_{\min } \geq I .{ }^{46}$ Furthermore, moving from a fixed term contract to the optimal contract can lead to substantial welfare gains. ${ }^{47}$

Consider next a low demand project. A PVR auction will implement the optimal contract in this case as well, as long as the government subsidizes the difference between the

\footnotetext{
${ }^{44}$ As noted in footnote 37 , this requires that demand grows at the same rate in all states.

${ }^{45}$ Uncertainty in $I$, which may be important in some projects, cannot be eliminated with a variable term contract.

${ }^{46}$ This case is considered in Engel et al. (2001).

${ }^{47}$ Depending on the degree of risk aversion and revenue uncertainty, Engel et al. (2001) find welfare gains between 16 and $64 \%$ of the upfront investment.
} 
winning bid and the present value of user fees collected. In this case firms end up bidding on a minimum income guarantee and the winning bid ensures a total revenue of $I$. Informational requirements are modest again, since the planner only needs to know that $v_{\max }<I$, and be able to verify revenue in each state. Note that the concession lasts forever in this case. We summarize both cases reviewed so far as follows:

Proposition 6 (High and low demand projects) The optimal contract can be implemented with a PVR auction, or a simple extensions thereof, for both high and low demand projects. Furthermore, bidders reveal I in the auction and there is no need to know $f$ or $u$.

Application: Evaluating least subsidy auctions Low demand projects are sometimes awarded to the firm that makes a bid for the smallest subsidy. That is, the government sets a fixed concession term $T$ and a user fee $p$, and firms bid the subsidy they require to build, operate and maintain the project.

Assume that cumulative user fee revenue accrued by time $t$ in state $v$ is equal to $\gamma(t, v) v$, with $\gamma$ strictly increasing in $t$, and $\lim _{t \rightarrow \infty} \gamma(t, v)=1$. Assuming a competitive auction, so that ex-ante rents are dissipated, the winning bid $S$ then satisfies:

$$
\int u(\gamma(T, v) v+S-I) f(v) d v=u(0),
$$

which means that the concessionaire will be forced to bear risk. ${ }^{48}$ It follows that

$$
S>I-\int \gamma(T, v) v f(v) d v,
$$

and since $\gamma(T, v) \leq 1$ we conclude that

$$
S>I-\mu_{v},
$$

where $\mu_{\nu}$ is the mean of $f(v)$.

By contrast, with a PVR auction the equilibrium outcome satisfies $S(v)=I-v$ and expected expenditures are equal to:

$$
\mathrm{E}[S]=I-\mu_{\nu} .
$$

With a minimum subsidy auction the subsidy is the same in all states of demand, which forces the concessionaire to bear risk. By contrast, the optimal contract features statecontingent subsidies that ensure that the concessionaire bears no risk. This leads to the somewhat counterintuitive result that the average subsidy paid out with a PVR auction is

\footnotetext{
${ }^{48}$ Note that $\lim _{t \rightarrow \infty} \gamma(t, v)=1$ and $v_{\min }<v_{\max }$ imply that $\gamma(T, v) v$ has to vary with $v$.
} 
lower than the winning bid in a lowest-subsidy auction. The concessionaire is forced to bear risk in the latter case, therefore demanding higher revenue on average, and a higher subsidy.

Proposition 7 (Sub-optimality of least subsidy auctions) A least-subsidy auction of a fixedterm concession is not optimal. Furthermore, for low demand projects this auction does not minimize the average subsidy paid out by the government.

\subsection{The general case}

Next we consider the case where the planner does not know if the project is high, intermediate or low demand. We also assume that the planner does not know firms' risk aversion, but does know the probability density $f(v) .{ }^{49}$ We show next how to implement the optimal contract with a simple scoring auction.

Proposition 8 (Optimality of the two-threshold auction) The following two-threshold, scoring auction implements the optimal contract:

- The government announces the probability density of expected discounted user fee revenue flow from the project, $f(v)$, and the parameter $\bar{\zeta}$ that summarizes the wedge between the shadow cost of public funds and subsidies.

- Firms bid on the minimum revenue guarantee, $m$, and the cap on their user fee revenue, $M$.

- The firm that bids the lowest value of the scoring function

$$
W(M, m)=M(1-F(M))+\int_{0}^{M} v f(v) d v+(1+\bar{\zeta}) \int_{0}^{m}(m-v) f(v) d v
$$

wins the concession.

Proof Since all firms are identical, the winning bid of the competitive auction minimizes the scoring function subject to firms' participation constraints. And since the scoring function is equal to the planner's objective function, where we use the fact that the optimal contract is characterized by thresholds $m$ and $M$, it follows that the winning bid maximizes the

\footnotetext{
${ }^{49}$ The government should be as informed about demand as third parties, because it either provides the service directly or it must compare the PPP with unbundled provision. Furthermore, substantial public planning is needed to design most PPP projects, and this requires an assessment of demand.
} 
planner's objective function subject to the firm's participation constraint, thereby solving the planner's problem.

What is the intuition underlying this result? Note first that the planner's objective function does not require knowledge of $I$. The objective function only depends on the probability distribution of the present value of revenue that the project can generate and the distortions associated with government expenditures, as summarized by $\bar{\zeta}$. By awarding the PPP to the bidder that maximizes his objective function, and assuming competitive bidding, the planner induces the concessionaire to solve society's problem without knowing the cost of the project or the firms' degree of risk aversion.

In the case of a high demand project, the two-threshold auction is equivalent to a PVR auction. If all states have high demand, any bid with $M=I$ and $m \leq I$ will win the auction. No subsidies are paid out and the concession term is shorter if demand is higher. Similarly, in the case of a low demand project, a bid with $m=I$ and $M \geq I$ wins the concession, since this time the upper threshold is irrelevant. In this case the two-threshold auction reduces to the extension of the PVR auction described above. However, the two-threshold auction is more general than a PVR auction, as it can be used for intermediate demand projects or, more importantly, for projects where the planner does not know whether the project is low, intermediate or high demand.

\section{Extensions}

This section extends our results in three directions. First, we consider a general case where demand responds to price changes and the concessionaire faces a standard convex shortrun cost curve. Second, we incorporate moral hazard, by assuming that demand responds to the concessionaire's unobservable effort. Finally, we reconsider the validity of the irrelevance result when the government faces temporary liquidity constraints.

\subsection{Price-responsive demand}

Assuming a totally inelastic demand simplifies the derivations, but is not realistic. We show next that the main insights obtained above carry through to the case with a priceresponsive demand. Once tolls are set appropriately, the optimal contract continues to be characterized by a minimum guarantee and a cap on revenues.

\section{The planner's problem}


There exists a continuum of verifiable demand states indexed by $\theta$ and described by a probability density $g(\theta)$. For tractability, we assume that the demand curve becomes known immediately after the project is built and remains constant over time. ${ }^{50}$

In the earlier sections we had a one-to-one correspondence between demand states, $\theta$, and the present-value of user fee revenue, $v$. Now the present value of user fee revenue in a given demand state depends on the user fee being charged. If user fee $p$ is charged both during and after the concession, we denote present discounted demand for the infrastructure in state $\theta$ by $Q(p, \theta)$, while the present discounted cost of producing $Q$ units is $c(Q, \theta)$, which is increasing and convex in $Q .{ }^{51}$ It follows that the concessionaire's discounted cash flow is:

$$
\Pi(p, \theta) \equiv p Q(p, \theta)-c(Q, \theta)
$$

which we assume increasing in $\theta$.

Assume that the planner gives weight $\eta \geq 0$ to the firm's discounted cash flow, and let $\operatorname{CS}(p, \theta)$ denote discounted consumer surplus if the user fee is $p$ in state $\theta$. Then

$$
H(p, \eta, \theta) \equiv \operatorname{CS}(p, \theta)+\eta \Pi(p, \theta)
$$

is the planner's discounted welfare. ${ }^{52}$

Let $p^{*}(\eta, \theta) \equiv \arg \max _{p} H(p, \eta, \theta)$. We assume that $p^{*}(\eta, \theta)$ increases with $\eta$ for a fixed value of $\theta$. That is, the user fee that maximizes (15) increases with the relative importance of producer's surplus. ${ }^{53}$ From the first order condition that characterizes $p^{*}(\eta, \theta)$ we have:

$$
\eta=-\frac{\mathrm{CS}_{p}\left(p^{*}(\eta, \theta), \theta\right)}{\Pi_{p}\left(p^{*}(\eta, \theta), \theta\right)}
$$

where $\mathrm{CS}_{p}$ and $\Pi_{p}$ denote the partial derivatives of CS and $\Pi$ with respect to $p$. As $\eta$ grows, $p^{*}(\eta, \theta)$ approaches the monopoly price for state $\theta$, denoted by $p^{M}(\theta)$. We also assume that $\Pi(p, \theta)$ is concave and strictly increasing in $p$ in the range $\left[p^{*}(1, \theta), p^{M}(\theta)\right]$.

For every demand state $\theta$, the planner chooses two prices, the user fee paid during the concession, $p^{C}(\theta)$, and the user fee collected by the government after the concession ends, $p^{G}(\theta)$. The planner also sets the optimal concession length $T(\theta)$. Let $r$ be the discount

\footnotetext{
${ }^{50}$ The results that follow extend easily to the case where the demand schedule grows at an exogenous rate that may vary over time and with $\theta$, since the price-elasticities of demand do not vary over time in this case as well. The problem becomes considerably harder when demand is allowed to evolve arbitrarily over time.

${ }^{51}$ This formulation makes it easy to extend the model to include congestion, which is important in the case of projects such as roads, tunnels and bridges. See, e.g., Engel et al. (2001).

${ }^{52}$ For notational simplicity, we use $\eta$ as a placeholder for $\alpha$ or other valuations of profits.

${ }^{53}$ See Engel et al. (2001) for an example with congestion where this property is derived from first principles. Of course, demand must be relatively inelastic.
} 
rate. For notational convenience we work with a monotonic transformation of $T(\theta), L(\theta) \equiv$ $e^{-r T(\theta)}$, so that $L$ decreases as $T$ grows, from a value of 1 when $T=0$ to a value of zero when $T=\infty$. Therefore the planner chooses functions $p^{C}(\theta), p^{G}(\theta), L(\theta)$ and $S(\theta)$, that solve the following program:

$$
\begin{gathered}
\max \int\left\{[1-L(\theta)] H\left(p^{C}(\theta), \alpha, \theta\right)+L(\theta) H\left(p^{G}(\theta), 1+\lambda, \theta\right)-[(1+\lambda)(1+\zeta)-\alpha] S(\theta)\right\} g(\theta) d \theta \\
\text { s.t. } \int u\left([1-L(\theta)] \Pi\left(p^{C}(\theta), \theta\right)+S(\theta)-I\right) g(\theta) d \theta=u(0) \\
0 \leq L(\theta) \leq 1 \\
S(\theta) \geq 0 .
\end{gathered}
$$

The first term in the integrand of (17a) is the planner's welfare during the concessionthe planner weighs the cash flow generated during this period by $\alpha$, because it accrues to the concessionaire. By contrast, the second term reflects welfare after the concession ends-during this period user fees are collected by the government and substitute for distortionary taxation, thus explaining why the planner's weight on instantaneous cash flow is $1+\lambda$. The third term in the objective function subtracts the cost of subsidies, which reflect the difference between the social cost of one dollar of subsidy, $(1+\lambda)(1+\zeta)$, and the weight the planner gives to an additional dollar in the concessionaire's pocket, $\alpha$. As before, the terms $\alpha I$ and $\mathscr{E}$ are omitted because they do not depend on the planner's choice variables.

\section{The optimal contract}

While the determination of optimal user fees is no longer trivial, the structure of the optimal contract remains identical to the case of perfectly inelastic demand. Thus, the present value of the cash flow received by the concessionaire is equal to $M$ across all high demand states, and $m$ across low demand states, with $m<M$. As before, the cash flow received by the concessionaire in intermediate demand states lies between $m$ and $M$. Moreover, high, intermediate and low demand projects are defined as before. The following proposition characterizes the optimal risk-sharing contract which solves program (17a)(17d).

\section{Proposition 9 (Taxonomy of projects) Projects can be classified into three types:}

(i) A project is high demand if and only if $\Pi\left(p^{*}(1+\lambda, \theta), \theta\right) \geq I$ for all states $\theta$. The concessionaire receives cash flow I in all states of demand, the concession term is finite, and the government collects $\Pi\left(p^{*}(1+\lambda, \theta), \theta\right)-I$. Moreover, $p^{C}=p^{G}=p^{*}(1+\lambda, \theta)$. 
(ii) A project is low demand if and only if $\Pi\left(p^{*}((1+\lambda)(1+\zeta), \theta), \theta\right)<I$. The concessionaire receives cash flow $I$ in all states of demand, the concession term is indefinite, and the government pays $I-\Pi\left(p^{*}((1+\lambda)(1+\zeta), \theta), \theta\right)$. Moreover, $p^{C}=p^{*}((1+\lambda)(1+\zeta), \theta)($ and $p^{G}$ is irrelevant).

(iii) A project is intermediate demand if and only if there exists at least one state $\theta$ such that

$$
\Pi\left(p^{*}(1+\lambda, \theta), \theta\right)<I<\Pi\left(p^{*}((1+\lambda)(1+\zeta), \theta), \theta\right)
$$

For these projects, the optimal contract is characterized by thresholds $m$ and $M$, with $m<I<M$, as follows. ${ }^{54}$

- A state $\theta$ is high demand if and only if $\Pi\left(p^{*}(1+\lambda, \theta), \theta\right)>M$. The concession term is finite and the user fee is $p^{*}(1+\lambda, \theta)$, both during and after the concession. The concessionaire's discounted cash flow is $M$ and the government collects $\Pi\left(p^{*}(1+\lambda, \theta), \theta\right)-M$.

- A state $\theta$ is low demand if and only if $\Pi\left(p^{*}((1+\lambda)(1+\zeta), \theta)<m\right.$. The user fee is $p^{*}((1+\lambda)(1+\zeta))$, the concession lasts indefinitely, and the concessionaire receives a subsidy equal to $m-\Pi\left(p^{*}((1+\lambda)(1+\zeta), \theta)\right)$.

- A state $\theta$ is intermediate demand if and only if: ${ }^{55}$

$$
m \leq \Pi\left(p^{*}(1+\lambda, \theta), \theta\right)<\Pi\left(p^{*}((1+\lambda)(1+\zeta), \theta), \theta\right) \leq M
$$

The concession lasts indefinitely but no subsidies are paid. The user fee $p^{*}(\eta(\theta), \theta) \in$ $\left[p^{*}(1+\lambda, \theta), p^{*}((1+\lambda)(1+\zeta), \theta)\right]$ is determined by solving for $\eta$ in:

$$
\frac{\eta-\alpha}{(1+\lambda)(1+\zeta)-\alpha} u^{\prime}(m-I)=u^{\prime}\left(\Pi\left(p^{*}(\eta, \theta)\right)-I\right)=\frac{\eta-\alpha}{1+\lambda-\alpha} u^{\prime}(M-I) .
$$

\section{Proof See Appendix D.4.}

\section{The economics of optimal user fees}

We now discuss how user fees are optimally set, thereby providing the intuition for the results in Proposition 9. Consider first $p^{G}$, the user fee after the concession ends. There

\footnotetext{
${ }^{54}$ As before, we assume $u^{\prime}\left(v_{\min }-I\right)>(1+\bar{\zeta}) u^{\prime}\left(\nu_{\max }-I\right)$. If this is not the case, then the optimal policy is described along the lines of footnote 40 .

${ }^{55}$ The assumptions we made $-p^{*}(\eta, \theta)$ increasing in $\eta$ and $\Pi(p, \theta)$ increasing and concave for $p \in$ $\left(p^{*}(1, \theta), p^{M}(\theta)\right)$-ensure that $\Pi\left(p^{*}(1+\lambda, \theta)<\Pi\left(p^{*}((1+\lambda)(1+\zeta), \theta)\right)\right.$. Therefore, our taxonomy of states creates a partition of the set of possible states.
} 
are no more profits for the concessionaire, so the planner just maximizes $H\left(p^{G}(\theta), 1+\lambda, \theta\right)$. Hence $\eta=1+\lambda$ in equation (16) and $p^{G}(\theta)=p^{*}(1+\lambda, \theta)$.

The economic intuition is that when demand is responsive to user fees there is an additional margin. The cash flow generated by user fees in each state increases with $p$ as long as $p<p^{M}$. Thus, it is optimal to depart from marginal cost pricing as long as the distortion at the margin is smaller than the cost of the alternative source of funding at the margin. If $\varepsilon$ is the elasticity of demand and $c_{q}$ is the short-run marginal cost, simple manipulations show that at the optimum the Lerner margin that maximizes (15) is such that

$$
\frac{p^{*}-c_{q}}{p^{*}}=\frac{\lambda}{1+\lambda} \times \frac{1}{\varepsilon}
$$

i.e., the planner chooses a user fee that creates a distortion commensurate with the cost of public funds.

The same principle applies, mutatis mutandis to the different types of demand states during the life of the concession. Consider optimal user fees during the concession. In a high demand state, $p^{C}$ must solve

$$
\begin{gathered}
\max _{p^{C}, L}\left\{(1-L) H\left(p^{C}, \alpha\right)+L H\left(p^{*}(1+\lambda)\right)\right\} \\
\text { s.t. } \quad(1-L) \Pi\left(p^{C}\right)=K,
\end{gathered}
$$

where $K$ is a constant and we have omitted $\theta$ to reduce clutter. The interpretation of this program is that if the concessionaire is to receive cash flow $K$ in present value under the optimal contract, then the most efficient price is $p^{C}$.

The key to our result is that $L$ is a function of $p^{C}$ in the constraint, since a higher user fee shortens the concession. Thus, we use the constraint to get rid of $L$, and replacing in the objective function, the optimal user fee must solve

$$
\max _{p^{C}}\left\{\frac{\operatorname{CS}\left(p^{C}\right)-H\left(p^{*}(1+\lambda)\right)}{\Pi\left(p^{C}\right)}\right\} .
$$

The FOC leads to

$$
H\left(p^{*}(1+\lambda)\right)=\operatorname{CS}\left(p^{C}\right)-\frac{\mathrm{CS}_{p}\left(p^{C}\right)}{\Pi_{p}\left(p^{C}\right)} \Pi\left(p^{C}\right)
$$

which, as follows from (16), implies that $p^{C}=p^{*}(1+\lambda)$ is optimal.

It may seem surprising at first sight that $p^{C}=p^{*}(1+\lambda)$, because the planner values a dollar in the concessionaire's pocket at $\alpha<1+\lambda$. Nevertheless, as the constraint in program (19a)-(19b) shows, the planner can recover the extra cash flow that the concessionaire re- 
ceives in a high demand state as a result of a higher $p^{C}$ because the concession is shorter. This implies that at the margin the higher revenue generated by raising the user fee during the concession substitutes for distortionary taxation after the concession ends. Hence, $p^{C}=p^{*}(1+\lambda)$ is optimal.

In a low demand state the user fee must solve

$$
\begin{gathered}
\max _{\left\{p^{C}, S\right\}}\{H(p, \alpha)-[(1+\lambda)(1+\zeta)-\alpha] S\} \\
\text { s.t. } \quad \Pi\left(p^{C}\right)+S=K
\end{gathered}
$$

which, after using the constraint to get rid of $S$, reduces to

$$
\max _{p^{C}}\left\{\operatorname{CS}\left(p^{C}\right)+(1+\lambda)(1+\zeta) \Pi\left(p^{C}\right)\right\}
$$

It follows that $p^{C}=p^{*}((1+\lambda)(1+\zeta))$ is optimal. In low demand states the planner can recover any extra dollar of user fee revenue received by the concessionaire by lowering subsidy $S$. Hence, at the margin the higher revenue generated by raising the user fee during the concession substitutes for subsidies and it pays to distort the use of the project until the Lerner margin reaches $\frac{(1+\lambda)(1+\zeta)-1}{(1+\lambda)(1+\zeta)} \times \frac{1}{\varepsilon}$.

Finally, consider an intermediate demand state. On the one hand, in this state $p^{*}((1+$ $\lambda)(1+\zeta))$ generates more cash flow than the cap $m$ allows, and at that point user fee revenue does not substitute for subsidies at the margin. Thus, setting $p^{C}=p^{*}((1+\lambda)(1+\zeta))$ would reduce the use of the project by too much. On the other hand, $p^{*}(1+\lambda)$ generates less revenue than required by the revenue cap $M$. Hence, $p^{C}=p^{*}(1+\lambda)$ would lead to excessive use of the facility. This is expressed formally by the following condition:

$$
\frac{\eta-\alpha}{(1+\lambda)(1+\zeta)-\alpha} u^{\prime}(m-I)=u^{\prime}\left(\Pi\left(p^{*}(\eta)\right)-I\right)=\frac{\eta-\alpha}{1+\lambda-\alpha} u^{\prime}(M-I) .
$$

\section{Finding $m$ and $M$}

In section 3 there existed a one-to-one relationship between demand states and user's willingness to pay for the project, allowing us to set $v=\theta$. As mentioned above, when demand responds to user fees there is no one-to-one relation between demand state's, $\theta$, and user's willingness to pay for the project, $v$. Nonetheless, demand uncertainty can be conveniently summarized by the joint distribution of the flow of profits generated by the project for two particular user fees, $p^{*}(1+\lambda)$ and $p^{*}((1+\lambda)(1+\zeta))$, and this distribution 
can be used later to characterize the thresholds $m$ and $M$ that define intermediate demand states.

We denote the joint density of $\Pi\left(p^{*}(1+\lambda, \theta), \theta\right)$ and $\Pi\left(p^{*}((1+\lambda)(1+\zeta), \theta), \theta\right)$ by

$$
f\left(w_{1+\lambda}, w_{(1+\lambda)(1+\zeta)}\right),
$$

and the corresponding marginal c.d.f.s. by $F_{1+\lambda}\left(w_{1+\lambda}\right)$ and $F_{(1+\lambda)(1+\zeta)}\left(w_{(1+\lambda)(1+\zeta)}\right)$. Figure 2 depicts a partition of the $\left(w_{1+\lambda}, w_{(1+\lambda)(1+\zeta)}\right)$-space into high, intermediate and low demand states, for given values of $m$ and $M$. Since $w_{(1+\lambda)(1+\zeta)}$ is always larger than $w_{1+\lambda}$, the joint density only has mass above the 45 -degree line. The lower-left triangle depicts demand states where user fees add up to less than $m$ in present value and subsidies are handed out. By contrast, user fee revenue in states in the upper-right triangle adds up to more than $M$ and the government obtains revenue in these states.

Figure 2: Partition of $\left(w_{1+\lambda}, w_{(1+\lambda)(1+\zeta)}\right)$-space into high, intermediate and low demand states

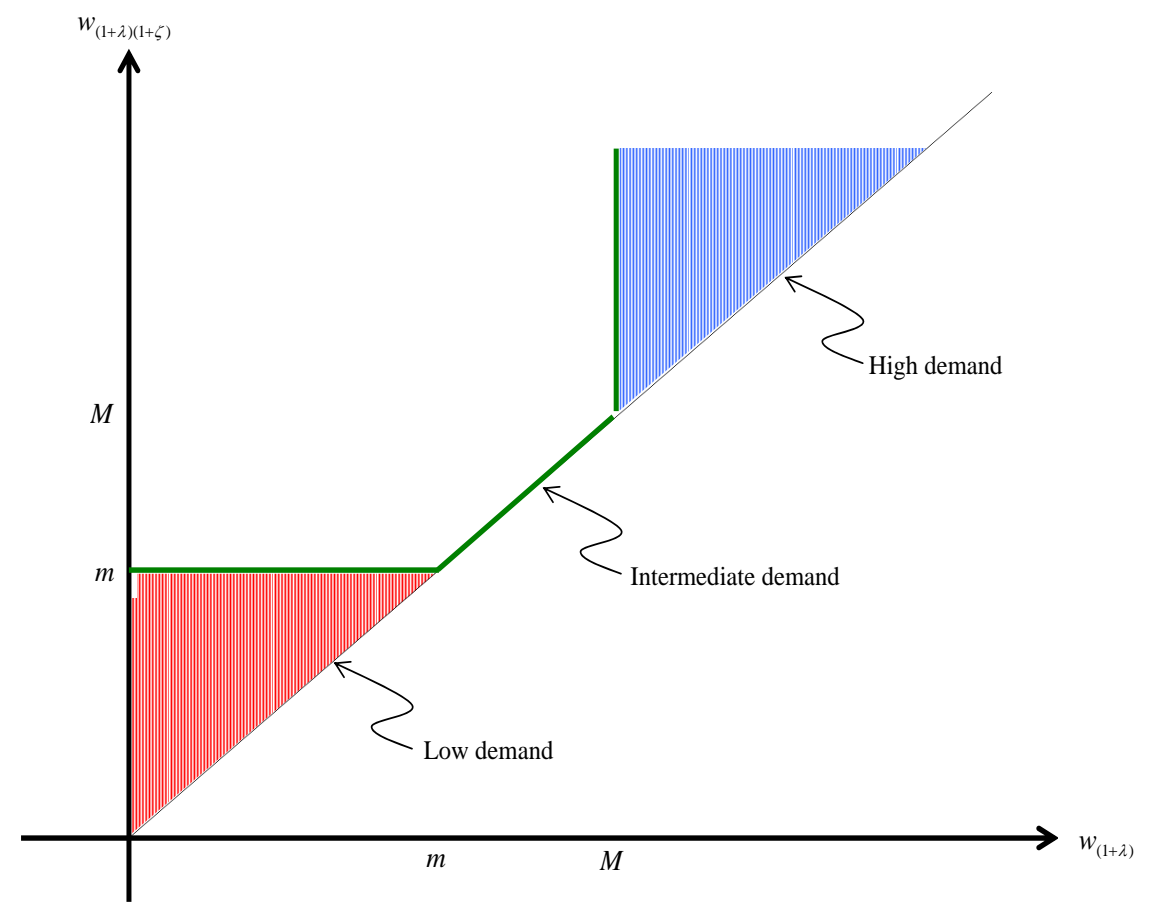

This characterization of uncertainty can be used to find $m$ and $M$ for an intermediate 
demand project:

Proposition 10 For an intermediate demand project, $m$ and $M$ are characterized by the concessionaire's participation constraint:

$$
\begin{aligned}
& F_{(1+\lambda)(1+\zeta)}(m) u(m-I)+\left(1-F_{1+\lambda}(M)\right) u(M-I) \\
& +\int_{0}^{M} \int_{m}^{\infty} u\left(\Pi\left(w_{(1+\lambda)(1+\zeta)}, w_{1+\lambda}\right)-I\right) f\left(w_{(1+\lambda)(1+\zeta)}, w_{1+\lambda}\right) d w_{(1+\lambda)(1+\zeta)} d w_{1+\lambda}=u(0),
\end{aligned}
$$

and

$$
u^{\prime}(m-I)=(1+\bar{\zeta}) u^{\prime}(M-I)
$$

where $1+\bar{\zeta}=[(1+\lambda)(1+\zeta)-\alpha] /(1+\lambda-\alpha)$ and $\Pi\left(w_{1+\lambda}, w_{(1+\lambda)(1+\zeta)}\right)$ is a shortcut for the expectation of $\Pi\left(p^{*}(\eta(\theta), \theta), \theta\right)$ conditional on $\Pi\left(p^{*}(1+\lambda, \theta), \theta\right)=w_{1+\lambda}$ and $\Pi\left(p^{*}((1+\lambda)(1+\right.$ $\zeta), \theta), \theta)=w_{(1+\lambda)(1+\zeta)}$

Proof The first expression is obtained from (17a) and the fact that the optimal policy is of the two-threshold type. The second expression follows from (18). Appendix D.5 includes an alternative derivation of the second expression that provides additional insights.

\section{Implementation}

The optimal contract can be implemented with a competitive auction. In common with the infinitely inelastic demand case, the planner does not need to know the up-front cost of the project or the firms' utility function. Firms bid on the lower and upper thresholds $m$ and $M$ and the contract is adjudicated to the concessionaire that bids the highest value of aggregate welfare. As before, aggregate welfare can be split up into the contribution of high, intermediate and low demand states, leading to: ${ }^{56}$

$$
W(M, m)=\mathbb{W}_{\text {high }}+\mathbb{W}_{\text {int }}+\mathbb{W}_{\text {low }}
$$

with

$$
\begin{aligned}
& \mathscr{W}_{\text {high }}=\int_{M}^{\infty}[\operatorname{CS}(w)+\alpha M+(1+\lambda)(w-M)] d F_{1+\lambda}(w) \\
& \mathscr{W}_{\text {int }}=\int_{0}^{M} \int_{m}^{\infty}\left[\operatorname{CS}\left(p^{*}\left(\eta\left(w_{(1+\lambda)(1+\zeta)}, w_{1+\lambda}\right)\right)+\alpha \Pi\left(\eta\left(w_{(1+\lambda)(1+\zeta)}, w_{1+\lambda}\right)\right)\right] f\left(w_{(1+\lambda)(1+\zeta)}, w_{1+\lambda}\right) d w_{(1+\lambda)(1+\zeta)} d w_{1+\lambda}\right. \\
& \mathscr{W}_{\text {low }}=\int_{0}^{m}[\operatorname{CS}(w)+\alpha m+(1+\lambda)(1+\zeta)(w-m)] d F_{(1+\lambda)(1+\zeta)}(w)
\end{aligned}
$$

\footnotetext{
${ }^{56}$ See Appendix D.5 for the derivation of the expressions that follow.
} 
Even though more information on demand is needed to set up the auction than in the case of inelastic demand, a good approximation to the optimal auction can be obtained if the government provides the distribution of the present value of profits under two particular sets of user fees: those corresponding to the shadow cost of subsidies for the project, $p^{*}((1+\lambda)(1+\zeta))$, and those reflecting the shadow cost of funds elsewhere in the economy, $p^{*}(1+\lambda)$.

\subsection{Moral hazard}

In this section we allow for demand that depends on unobservable and costly effort by the concessionaire. An additional motive to have the firm bear risk emerges in this case, as risk now helps induce optimal levels of effort by the concessionaire. As before, two thresholds, $m$ and $M$, suffice to partition states into high, intermediate and low demand states. Even though now total revenue collected by the concessionaire increases with $v$, subsidies are paid out only in low demand states $(v<m)$, while the government collects user-fees only in high demand states $(v>M)$.

\section{The planner's problem}

We embed the model of section 3 in a simple moral hazard framework. The concessionaire can exert costly effort, which affects the probability distribution of demand realizations. The density $f(\nu \mid \epsilon)$ summarizes uncertainty about the present discounted value of user fee revenue, for an indefinite contract, when the concessionaire chooses effort level $\epsilon{ }^{57}$ We assume the monotone likelihood ratio property (MLRP) holds, so that $\ell(\nu, \epsilon) \equiv$ $\frac{\partial f}{\partial \epsilon}(\nu \mid \epsilon) / f(\nu \mid \epsilon)$ is increasing in $v$ for all $\epsilon$; i.e., effort increases the probability of higher realizations of demand. The utility of the concessionaire, $U(y, \epsilon)=u(y)-k \epsilon, k>0$, is separable into net revenue and effort, where $y$ denotes the present value of user fees collected by the concessionaire and $\epsilon \geq 0$ the concessionaire's effort.

The planner chooses effort $\epsilon$, and revenue and subsidy schedules $R(v)$ and $S(v)$, to solve

\footnotetext{
${ }^{57}$ In this section, effort is an action undertaken by the concessionaire during the construction phase that affects demand for the infrastructure service both during and after the concession.
} 
the following program

$$
\begin{gathered}
\min _{\{R(\nu), S(\nu), \epsilon\}} \int\{(1+\lambda-\alpha) R(\nu)+[(1+\lambda)(1+\zeta)-\alpha] S(\nu)-(1+\lambda) \nu\} f(\nu \mid \epsilon) d \nu \\
\text { s.t. } \quad \int u(R(\nu)+S(\nu)-I) f(\nu \mid \epsilon) d \nu \geq u(0)+k \epsilon, \\
\epsilon=\arg \max _{\epsilon^{\prime}}\left\{\int u(R(\nu)+S(\nu)-I) f\left(\nu \mid \epsilon^{\prime}\right) d \nu-k \epsilon^{\prime}\right\}, \\
0 \leq R(\nu) \leq \nu, \\
S(\nu) \geq 0 .
\end{gathered}
$$

Comparing program (6a)-(6d) with program (23a)-(23e) it can be seen that the term $(1+\lambda) v$ has been added because now effort affects the p.d.f. of users' present discounted willingness to pay. Constraint (23b) is the concessionaire's participation constraint, and (23c) is the incentive compatibility constraint.

Under standard assumptions, ${ }^{58}$ we can use the First Order Approach to examine the properties of the solution. The concessionaire's incentive compatibility constraint can be replaced by

$$
\int u(R(\nu)+S(\nu)-I) \ell(\nu, \epsilon) f(\nu \mid \epsilon) d v=k
$$

Denoting by $\mu>0$ the multiplier associated with (23b) and $\tau>0$ the multiplier associated with (24), ${ }^{59}$ we have that the Lagrangian of the problem is:

$$
\begin{aligned}
\mathscr{L}= & \int\{(1+\lambda-\alpha) R(v)+[(1+\lambda)(1+\zeta)-\alpha] S(\nu)-(1+\lambda) \nu\} f(\nu \mid \epsilon) d v \\
& -\mu\left[\int u(R(v)+S(v)-I) f(\nu \mid \epsilon) d v-k \epsilon\right]-\tau \int u(R(\nu)+S(\nu)-I) \ell(\nu, \epsilon) f(\nu \mid \epsilon) d v .
\end{aligned}
$$

The first order condition w.r.t. to $\epsilon$, combined with (24), provides an expression for $\tau$ :

$$
\tau=\frac{\int\{(1+\lambda-\alpha) R(\nu)+[(1+\lambda)(1+\zeta)-\alpha] S(\nu)-(1+\lambda) \nu\} \ell(\nu, \epsilon) f(\nu \mid \epsilon) d v}{\int u(R(\nu)+S(\nu)-I) \frac{\partial^{2} f}{\partial e^{2}}(\nu, \epsilon) d v}
$$

\section{Optimal contract when $\zeta=0$}

When $\zeta=0$, it follows from the Lagrangian (25) that the distinction between user fees and subsidies is irrelevant, as before, and the optimal policy can be described exclusively

\footnotetext{
${ }^{58}$ E.g., strict concavity of the agent's utility as a function of $\epsilon$ and the convexity of the distribution function condition, see, e.g., Proposition 5.2 in Laffont and Martimort [2002].

${ }^{59}$ See Appendix E for formal proofs showing that $\mu>0$ and $\tau>0$.
} 
in terms of total revenue, $\mathscr{T}(\nu) \equiv R(\nu)+S(\nu)$. The irrelevance result also holds in this case, and $\lambda>0$ does not make the case for a PPP.

It is no longer optimal to grant full insurance to the concessionaire. Indeed, the FOC with respect to $\mathscr{T}(\nu)$ leads to

$$
u^{\prime}(\mathscr{T}(\nu)-I)=\frac{1+\lambda-\alpha}{\mu+\tau \ell(\nu, \epsilon)}
$$

and the MLRP implies that $\mathscr{T}(\nu)$ is strictly increasing in $v$. It also follows that, contrary to the results obtained in section 3 , the concessionaire's average revenue is larger than $I$, both because he bears risk and because he must be compensated for exerting costly effort.

In our framework outright privatization corresponds to $\mathscr{T}(\nu)=v-K$, with $K$ constant. It follows from (26) that, generically, privatization is not optimal, since the utility and likelihood ratio functions, $u$ and $\ell$, are exogenous and there is no reason why the first order condition above should hold. The intuitive explanation is that standard privatization assigns residual demand risk to the firm in all states, while the first-order condition (26) suggests a more subtle risk sharing arrangement, i.e., one that limits the risk borne by the firm in some states.

To further characterize the optimal contract with moral hazard, we assume that $\mathscr{G}(\nu, \epsilon) \equiv$ $u^{\prime}(\nu-I)[\mu+\tau \ell(\nu, \epsilon)]$ is strictly decreasing in $\nu$ for all feasible $\epsilon$, which we refer to as the "single-crossing assumption" in what follows. ${ }^{60}$ This assumption implies that, given $\mu$ and $\tau$, there exists $M$ such that

$$
u^{\prime}(M-I)=\frac{1+\lambda-\alpha}{\mu+\tau \ell(M, \epsilon)} .
$$

The optimal contract then falls into one of the three following cases:

Proposition 11 Assume $\zeta=0, \mathscr{G}(\nu, \varepsilon) \equiv u^{\prime}(\nu-I)[\mu+\tau \ell(\nu, \epsilon)]$ strictly decreasing in $v$ for all feasible $\varepsilon$, and define $M$ as in (27). Then:

(i) If $M<v_{\min }: \mathscr{T}(v)<v$ for all $v \in\left[v_{\min }, v_{\max }\right]$.

(ii) If $M>v_{\max }: \mathscr{T}(v)>v$ for all $v \in\left[v_{\min }, v_{\max }\right]$.

(iii) If $M \in\left[v_{\min }, v_{\max }\right]: \mathscr{T}(\nu)<v$ for $v \in\left[v_{\min }, M\right)$ and $\mathscr{T}(\nu)>v$ for $v \in\left(M, v_{\max }\right]$.

\footnotetext{
${ }^{60}$ To derive this condition from first principles is not trivial, since $\mu$ and $\tau$ are multipliers that vary with the problem's parameters and, at least in principle, can take any positive value. Appendix E derives sufficient conditions for $\partial \mathscr{G} / \partial v<0$, in terms of the problem's deep parameters, for the case of an exponential distribution and constant absolute risk aversion. As discussed in that appendix, all we really need is a weaker single-crossing condition.
} 


\section{Proof See Appendix E.}

The above proposition is a standard result in principal-agent theory: To induce socially optimal effort, subject to the incentive compatibility constraint, the principal designs a contract where the agent bears risk. The increase in demand compensates for the additional revenue required by the agent because he is not fully insured. Furthermore, the MLRP ensures that total revenue is increasing in $v$, and there exists a threshold $M$ such that the firm is subsidized when $v<M$ while the government shares in user fee revenue when $v>M$. Depending on the value of $M$, the project may be high or low demand, but there are no intermediate demand projects, i.e., those that, for a range of values of $v$, have no effect on government finances. For these states to appear in the optimal contract, it is necessary that $\zeta>0$. We turn to this case next.

\section{Optimal contract when $\zeta>0$}

Figure 3 depicts the optimal contract when $\zeta>0$. To derive this contract formally, we first note that user-fees dominate subsidies as a source of revenue for the firm when $\zeta>0$. Therefore subsidy financing only takes place when $R(v)=v$. It follows that the FOC with respect to $R(v)$ for a state $v$ where the concession term is finite leads to:

$$
u^{\prime}(R(v)-I)=\frac{1+\lambda-\alpha}{\mu+\tau \ell(\nu, \epsilon)}
$$

while the FOC with respect to $S(v)$ for a state where subsidies are paid out yields

$$
u^{\prime}(\nu+S(\nu)-I)=\frac{(1+\lambda)(1+\zeta)-\alpha}{\mu+\tau \ell(\nu, \epsilon)} .
$$

Define $M$ and $m$ via:

$$
\begin{gathered}
u^{\prime}(M-I)=\frac{1+\lambda-\alpha}{\mu+\tau \ell(M, \epsilon)}, \\
u^{\prime}(m-I)=\frac{(1+\lambda)(1+\zeta)-\alpha}{\mu+\tau \ell(m, \epsilon)},
\end{gathered}
$$

given $\mu, \tau$ and $\epsilon$. It then follows from $u^{\prime \prime}<0$, (28), (29), and the assumption that $\mathscr{G}(\nu, \epsilon)$ is decreasing in $v$, that states with $v \geq M$ are high demand states, while states $v \leq m$ are low demand states, in the sense that the government collects user fees in the former case and pays subsidies in the latter.

Contrary to the optimal contract for the case with no moral hazard depicted in Figure 1, the concessionaire's revenue is not equal across all high demand states or all low demand 
Figure 3: Optimal contract with moral hazard and $\zeta>0$

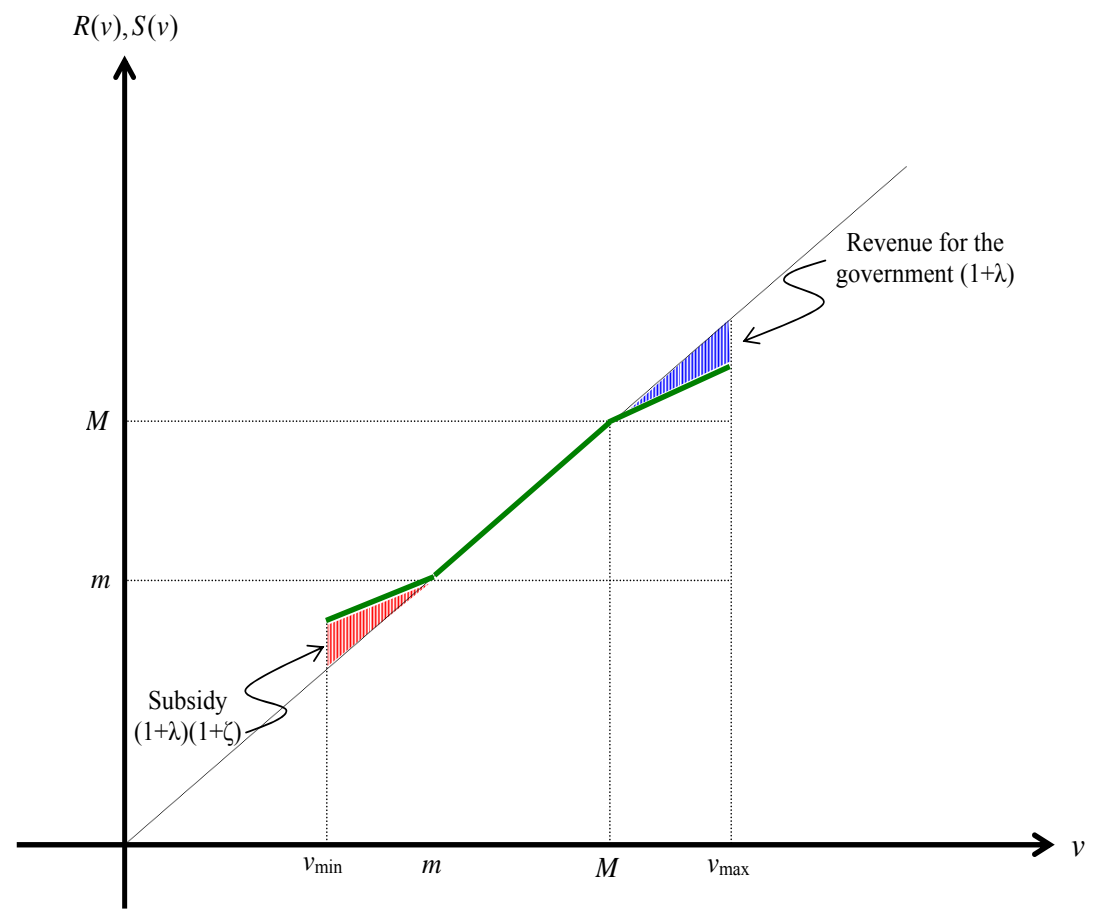


states. But the gap between $m$ and $M$ emerges for precisely the same reason as before, namely that subsidy finance is more expensive than user fee revenue at the margin. Moral hazard does not change the basic structure of the optimal contract, even though now the concessionaire's total revenue is strictly increasing in $v$.

Figure 3 shows that for an intermediate demand project with $\zeta>0$ we have a range of values of $v$ where the contract lasts indefinitely and there are no subsidies. This range of intermediate demand states (and intermediate demand projects) emerges only when $\zeta>0$, leading to an increase in risk borne by the concessionaire beyond the level predicted by the standard principal-agency model for the case $\zeta=0$. To make this statement precise, we note that it follows from the MLRP and the definition of $m$ and $M$ that if $v_{H}$ denotes a high demand state and $v_{L}$ a low demand state, then:

$$
u^{\prime}\left(\nu_{L}-I\right)=(1+\bar{\zeta}) \frac{\mu+\tau \ell\left(v_{H}, \epsilon\right)}{\mu+\tau \ell\left(v_{L}, \epsilon\right)} u^{\prime}\left(v_{H}-I\right)
$$

The need to induce effort would make revenue in state $v_{H}$ greater than that in state $v_{L}$ even when $\zeta=0$. But because $\zeta>0$, (which is equivalent to $\bar{\zeta}>0$ ), the difference in revenue between states is amplified, since (31) implies

$$
u^{\prime}(m-I)>(1+\bar{\zeta}) u^{\prime}(M-I)
$$

while without effort we have an equality (see (12)). For example, for CARA utility with coefficient of absolute risk aversion $A$ :

$$
M-m=\frac{1}{A}\left[\log (1+\bar{\zeta})+\log \left(\frac{\mu+\tau \ell(M, \epsilon)}{\mu+\tau \ell(m, \epsilon)}\right)\right],
$$

which, because of the MLRP, is larger than the corresponding expression when effort does not matter:

$$
M-m=\frac{1}{A} \log (1+\bar{\zeta})
$$

It is time to take stock:

Proposition 12 Assume $\zeta>0, \mathscr{G}(\nu, \varepsilon) \equiv u^{\prime}(\nu-I)[\mu+\tau \ell(\nu, \epsilon)]$ strictly decreasing in $v$ for all feasible $\varepsilon$, and define $M$ and $m$ as in (30a)-(30b). Then $\mathscr{T}(v)$ is increasing in $v$ and:

(i) If $M<v_{\min }: \mathscr{T}(v)=R(v)<v$ for all $v \in\left[v_{\min }, v_{\max }\right]$ and no subsidies are paid (high demand project).

(ii) If $m>v_{\max }: \mathscr{T}(v)>v$ for all $v \in\left[v_{\min }, v_{\max }\right]$ and subsidies are paid in all states (low demand project). 
(iii) If $v_{\min }<m<M<v_{\max }$ :

- $v>M$ corresponds to high demand states, with no subsidies and a finite contract length.

- $v<m$ corresponds to low demand states, with indefinite contracts and subsidies

- $m<v<M$ corresponds to intermediate demand states, with indefinite contracts and no implications for the government budget.

\section{Application: Profit sharing and profit guarantees in the real world}

In many PPP contracts the counterpart of minimum revenue guarantees has been a revenue (and sometimes profit) sharing clause. We argue that these contracts are far from optimal when effort matters.

The optimal contract involves both a state-dependent subsidy in low demand states and a state-dependent revenue cap above which the government collects all revenues. Moreover, the concession term is state contingent in high demand states, and the concession lasts indefinitely when subsidies are paid out. Both characteristics are seldom, if ever, observed in real world PPP contracts. Normally, the guarantee leads to a constant revenue for the concessionaire in low demand states, and the term of the concession is fixed and finite.

Note, moreover, that the choice between the incentive contract described above and the contract for the case without moral hazard discussed earlier (sections 3 and 5.1) depends on the extent to which demand is exogenous, or should it be endogenous, the extent to which the concessionaire's actions affecting demand are enforceable. When these conditions hold—as in the case for highways, which account for more than half of the world's expenditures on $\mathrm{PPPs}^{61}$ — the contract without moral hazard applies and profit sharing arrangements are not justified. By contrast, when the optimal contract needs to be high powered, then an incentive contract is desirable.

\subsection{Liquidity constrained government}

An often mentioned argument in favor of PPPs is that they allow governments to invest in socially desirable projects during periods of severe credit constraints. A simple extension of the framework developed in this paper can be used to analyze the validity of this assertion.

\footnotetext{
${ }^{61}$ See Hemming (2006).
} 
The liquidity argument in favor of PPPs can be captured within our framework, in reduced form, by allowing the marginal cost of public funds to change over time. More precisely, we assume that due to liquidity constraints, the current marginal cost of funds is $1+\lambda_{0}$, which is higher than the future cost of funds $1+\lambda_{1}$. This implies that when comparing the option of providing an infrastructure project in the traditional way, i.e., via upfront subsidies, versus provision by means of a PPP, the initial investment will have a higher cost of funds for the government relative to the future revenues from user fees. In order to make our point, we consider the case in which there is no inefficiency in government spending, so $\zeta=0$.

The objective function (4) minimized by the social planner then becomes:

$$
\int\left[\left(1+\lambda_{1}-\alpha\right) R(\nu)+\left(1+\lambda_{0}-\alpha\right) S(\nu)\right] f(\nu) d v
$$

Thus, even though $\bar{\zeta}=0$ in this case, the planner's problem is analogous to the problem she faces when the government is productively inefficient, with $\left(1+\lambda_{0}-\alpha\right) /\left(1+\lambda_{1}-\alpha\right)$ in place of $1+\bar{\zeta}$.

It follows that the irrelevance result does not hold when the government is credit constrained, since traditional procurement requires upfront spending, which is more expensive than financing the project via future user fees under a PPP. Hence there is a presumption in favor of PPPs as compared to the traditional provision of infrastructure. Furthermore, the results derived in sections 3 and 4 on the optimal PPP contract can be applied to show that for intermediate demand projects a credit-constrained government will have the firm bear additional risk in order to save on costly upfront subsidies.

Some caveats regarding this argument in favor of PPPs are in order. First, the argument fails if the cost of public funds is high not only in the present but also in the foreseeable future. ${ }^{62}$ In this case both $\lambda_{0}$ and $\lambda_{1}$ are high, and there is no a priori justification for assuming the latter is lower than the former. The irrelevance result continues holding and liquidity constraints do not justify PPPs. Second, our framework does not include the timing of the project among the planner's decision variables. Adding the option value of waiting would not be difficult, and may lead to optimally postponing a project if the marginal costs of funds is expected to fall in the future.

Finally, observe that the failure of the irrelevance result is due to an inability to commit by the government: in principle, the government should be able to issue a bond (to finance the project) whose repayments are tied to the revenue stream generated by user fees from

\footnotetext{
${ }^{62}$ Note that this may be the case of several Latin American countries, which cycle between periods of liquidity constraints and liquidity abundance. It also seems appropriate for some African countries with poor government policies, and which appear to be permanently credit constrained.
} 
the project. In that case, the liquidity constraint would have no effect on the choice between PPP or standard provision of infrastructure. ${ }^{63}$

\section{Conclusion: Are PPPs public or private?}

As the worldwide enthusiasm about privatizations waned, PPPs began to boom. One reason governments like PPPs is that they provide a temporary transfer of most of the benefits of ownership of the assets at stake to private firms, thus avoiding criticism from those who oppose privatization. At the same time, because some ownership rights are transferred, governments can also claim that private sector participation is being advanced.

This raises the question of whether PPPs should be viewed as temporary privatizations, or simply as another option to procure public services. Some characteristics of PPPs clearly resemble privatization. For example, Bennet and Iossa (2006) argue that in addition to bundling, a PPP gives the concessionaire ownership rights over assets and control rights over how to produce the service. ${ }^{64}$ Furthermore, our analysis has shown that the optimal risk-sharing contract allocates all user fees to the concessionaire for as long as the concession lasts, as in the case of a privatized firm.

Yet this paper's results can be used to argue that, as far as the risk profile of the government's budget is concerned, PPPs are much closer to public provision than to privatization. Our starting point to derive this insight is that when thinking about the risk allocation implied by PPPs, what matters is the intertemporal risk profile of cash flows, not the year-toyear risk profile. This has interesting implications: for low and high demand projects, an optimal PPP contract replicates the net cash flow streams of conventional ('public') provision, state by state (see Table 1, which assumes an additive risk premium). Essentially, all residual risk is transferred to the government, and the concessionaire recovers $I$ in all states, as in the case of conventional provision.

For intermediate demand projects, our results show that a risk-sharing arrangement is optimal. The extent to which the firm bears risk now depends on the extent to which subsidies are a more costly source of financing than user fees, as captured by the parameter $\bar{\zeta}$. When subsidy financing is very inefficient, it is too expensive to reduce the firm's risk

\footnotetext{
${ }^{63}$ Sovereign governments, specially in developing countries, may still face this problem, since they cannot guarantee that in the future they will not expropriate the revenue stream to solve other, more urgent needs. In this they differ from the local authorities of developed countries, which are constrained by overarching national legislation from diverting the revenue stream, and use these instruments to finance infrastructure projects.

${ }^{64}$ Bennet and Iossa (2006) argue that bundling is not a sufficient condition to justify a PPP since the could contract a bundled service, while still keeping ownership of the assets and user fees, as under conventional provision.
} 
Table 1: Average discounted budget: public provision vs. PPPs

\begin{tabular}{lccc}
\hline \hline & Public provision & PPP & Privatization \\
& $-I$ & 0 & $\int f(v) d v-I-$ Risk Premium \\
Upfront surplus: & $\int f(v) d v$ & $\int f(v) d v-I$ & 0 \\
Discounted user fees: & $\int f(v) d v-I$ & $\int f(v) d v-I$ & $\int f(v) d v-I-$ Risk Premium \\
\hline Total: & & & \\
\hline
\end{tabular}

via subsidies, and it is best to have the firm bear most (sometimes all) of the risk. PPPs resemble privatizations in this case. On the other hand, if subsidy financing is only slightly less efficient than user-fee financing, the minimum income guarantee and the cap on user fee revenues that characterize the optimal contract are very similar, and the government bears most of the risk. As with high and low demand projects, risk sharing arrangements resemble public provision in this case.

Under privatization, the project is sold for a one-time payment and all risk is transferred to the firm. Moreover, the link between the project and the public budget is permanently severed. This is not the case with a PPP, where at the margin cash flows from the project always substitute for either taxes or subsidies. The conclusion, then, is that from a public finance perspective there is a strong presumption that PPPs are analogous to conventional provision-in essence, they remain public projects, and should be treated as such. 


\section{References}

[1] A. Akintola, M. Beck and C. Hardcastle, Public-Private Partnerships: Managing Risks and Opportunities. Oxford: Blackwell, 2003.

[2] K.J. Arrow and R.C. Lind, "Uncertainty and Public Investment Decisions," American Economic Review, 60, 364-78, 1970.

[3] J. Bennett and E. Iossa, "Building and Managing Facilities for Public Services," Journal of Public Economics, 90, 2143-60, 2006.

[4] A. Bentz, P. Grout and M. Halonen, "What Should Governments Buy from the Private Sector-Assets or Services?,” mimeo, University of Bristol, 2005.

[5] T. Besley and M. Ghatak, "Government Versus Private Ownership of Public Goods," Quarterly Journal of Economics, 116, 4, 1343-72, 2001.

[6] R. Brealey, I. Cooper and M. Habib, "Investment Appraisal in the Public Sector," Oxford Review of Economic Policy 13, 12-27, 1997.

[7] E. Chadwick, "Results of Different Principles of Legislation in Europe," Journal of the Royal Statistical Society A 22, 381-420, 1859.

[8] R. Daniels and M. Trebilcock, "Private Provision of Public Infrastructure: An Organizational Analysis of the Next Privatization Frontier," University of Toronto Law Journal, 46, 375-426, 1996.

[9] R. Daniels and M. Trebilcock, "An Organizational Analysis of the Public-Private Partnership in the Provision of Public Infrastructure." In P. Vaillancourt-Roseneau (ed.), Public-Private Policy Partnerships. Cambridge, Mass.: MIT Press, 2000.

[10] H. Demsetz, “Why Regulate Utilities,” Journal of Law and Economics, 11, 55-66, 1968.

[11] M. Dewatripont and P. Legros, "Public-Private Partnerships: Contract Design and Risk Transfer,” EIB Papers, 10, 120-145, 2005

[12] Economic Planning Advisory Commission (EPAC), Final Report of the Private Infrastructure Task Force, Australian Government Publishing Service, Canberra, 1995.

[13] E. Engel, R. Fischer, and A. Galetovic, "Least-present-value-of-revenue Auctions and Highway Franchising,” Journal of Political Economy, 109, 993-1020, 2001.

[14] E. Engel, R. Fischer, and A. Galetovic, "Privatizing Highways in Latin America: Fixing What Went Wrong," Economia, 4(1), 129-158, October 2003.

[15] M. Gerrard, "Public-Private Partnerships," Finance and Development, 38, 48-51, 2001.

[16] D. Grimsey and M. Lewis, The Economics of Public-Private Partnerships. Northampton: Edward Elgar, 2004. 
[17] D. Grimsey and M. Lewis, Public-Private Partnerships. Northampton: Edward Elgar, 2005.

[18] D. Grimsey and M. Lewis, "Public Private Partnerships and Public Procurement," Agenda, 14(2), 2007.

[19] P. Grout, “The Economics of the Private Finance Initiative," Oxford Review of Economic Policy, 13, 53-66, 1997.

[20] P. Grout and M. Stevens, “The Asessment: Financing and Managing Public Services,” Oxford Review of Economic Policy 19, 215-234, 2003.

[21] J. L. Guasch, Granting and Renegotiating Infrastructure Concessions: Doing it Right. Washington: The World Bank, 2004.

[22] R. Harstad and M. Crew, "Franchise Bidding Without Holdups: Utility Regulation with Efficient Pricing and Choice of Provider," Journal of Regulatory Economics, 15, 1999, 141-163.

[23] O. Hart, "Incomplete Contracts and Public Ownership: Remarks and an Application to Public-Private Partnerships," Economic Journal, 113, C69-C76, 2003.

[24] R. Hemming, "Public-Private Partnerships, Government Guarantees and Fiscal Risk”. Washington, DC: IMF, 2006.

[25] T. Irwin, Government Guarantees: Allocating and Valuing Risk in Privately Financed Infrastructure Projects. Washington: The World Bank, 2007.

[26] M. Klein, “The Risk Premium For Evaluating Public Projects,” Oxford Review of Economic Policy 13, 29-42, 1997.

[27] J.J. Laffont and D. Martimort, The Theory of Incentives, Princeton: Princeton University Press, 2002.

[28] J.J. Laffont and J. Tirole, A Theory of Incentives in Procurement and Regulation. Cambridge, Mass.: MIT Press, 1993.

[29] D. Martimort and J. Pouyet, "To Build or Not to Build: Normative and Positive Theories of Private-Public Partnerships," to appear in International Journal of Industrial Organization.

[30] R. Posner, “The Appropriate Scope of Regulation in Cable Television,” Bell Journal of Economics, 3, 1972, 335-358.

[31] M.H. Riordan and D.E.M. Sappington, "Awarding Monopoly Franchises," American Economic Review, 77, 1987, 375-387.

[32] E. Savas, Privatization and Public-Private Partnerships. New York: Chatam House Publishers, 2000. 
[33] D. Schrank and T. Lomax, Annual Mobility Report. Texas: Texas Transportation Institute, 2005.

[34] D. Spulber, Regulation and Markets, Cambridge Mass.: MIT Press, 1989.

[35] P. Starr, “The Meaning of Privatization,” Yale Law and Policy Review, 6, 6-41, 1988.

[36] G. Stigler, The Organization of Industry, Homewood: Richard D. Irwin, 1968.

[37] P. Vaillancourt-Roseneau, Public-Private Policy Partnerships. Cambridge: MIT Press, 2000.

[38] O.E. Williamson, "Franchise Bidding for Natural Monopolies-In General and with Respect to CATV," Bell Journal of Economics, 7, 1976, 73-104.

[39] O.E. Williamson, The Economic Institutions of Capitalism, New York: The Free Press, 1985. 


\section{Appendix}

\section{A When is a project socially valuable?}

\section{A.1 Model}

We define producer surplus as

$$
P S(v)=R(v)+S(v)-I .
$$

Let $\beta_{\mathrm{p}} \in[0,1]$ stand for the fraction of the private willingness to pay that can be collected by charging user fees over the life of the infrastructure project (this is a generalization of our assumption $\beta_{\mathrm{p}}=1$ in the body of the paper) and let $\mathscr{E}$ denote the externality generated by the project. The parameter $\beta_{\mathrm{p}}$ is less than one, for example, when charging user fees is politically unpopular, as is the case in a number of U.S. states with no toll roads. ${ }^{65,66}$ Consumer surplus then is: ${ }^{67}$

$$
\operatorname{CS}(v)=\lambda\left[\beta_{\mathrm{p}} v-R(v)\right]+[v-R(v)-(1+\lambda)(1+\zeta) S(v)]+\mathscr{E} .
$$

Hence

$$
\begin{aligned}
\operatorname{CS}(v)+\alpha P S(v) & =\lambda\left[\beta_{\mathrm{p}} v-R(v)\right]+[v-R(\nu)-(1+\lambda)(1+\zeta) S(v)]+\alpha(R(\nu)+S(\nu)-I)+\mathscr{E} \\
& =\left[\lambda \beta_{\mathrm{p}}+1\right] v-(1+\lambda-\alpha) R(\nu)-[(1+\lambda)(1+\zeta)-\alpha] S(\nu)-\alpha I+\mathscr{E} .
\end{aligned}
$$

Let $\gamma v$ be the maximum fraction of consumer willingness to pay that can be transferred to the concessionaire under a PPP. ${ }^{68}$ Clearly, $\gamma \leq \beta_{\mathrm{p}}$. Let $\left\{R^{*}(\nu), S^{*}(\nu)\right\}$ solve

$$
\begin{gathered}
\max _{\{R(v), S(v)\}} \int[\mathrm{CS}(v)+\alpha P S(v)] f(v) d v \\
\text { s.t. } \int u(R(v)+S(v)-I) f(v) d v \geq u(0), \\
0 \leq R(v) \leq \gamma v \\
S(v) \geq 0 .
\end{gathered}
$$

\footnotetext{
${ }^{65}$ Alternatively, $\beta_{\mathrm{p}}$ will be less than one in a toll road where the location of toll booths is suboptimal.

${ }^{66}$ The results that follow can be extended to the case where $\beta_{\mathrm{p}}$ depends on whether the project is provided publicly or privately. For example, $\beta_{\mathrm{p}}$ is smaller under public provision when higher user fees can be charged under private management. This extension can be used to analyze the case where government's use PPPs to commit to higher user fee collection.

${ }^{67}$ Note that the unpaid fraction $\left(1-\beta_{\mathrm{p}}\right)$ remains as part of consumer surplus with or without the project.

${ }^{68}$ This parameter can be used to model a legally mandated maximum length of a PPP (e.g. 50 years in Chile). $\beta_{\mathrm{p}}$, on the other hand, models the ability to appropriate user's willingness to pay.
} 
The expected social value of the project is

$$
S V \equiv \int\left\{\left[\lambda \beta_{\mathrm{p}}+1\right] \nu-(1+\lambda-\alpha) R^{*}(\nu)-[(1+\lambda)(1+\zeta)-\alpha] S^{*}(\nu)-\alpha I\right\} f(\nu) d v+\mathscr{E}
$$

We can now use (32) to explore the conditions required for $S V>0$.

\section{A.2 The social value of a project}

A high demand project In this case $I \leq \gamma v_{\min }, R^{*}(v)=I$ and $S^{*}(v)=0$ for all $v$. Then a high demand project is socially worthwhile if and only if

$$
S V=\int\left\{\left[\lambda \beta_{\mathrm{p}}+1\right] v-(1+\lambda) I\right\} f(\nu) d v+\mathscr{E} \geq 0 .
$$

If, in addition $\beta_{\mathrm{p}}=1$, then the condition simplifies to

$$
S V=\int(1+\lambda)(v-I) f(v) d v+\mathscr{E} \geq 0 .
$$

Note that in the case of a high demand project, the social value does not depend on $\alpha$. Since $\lambda>0$, the social value of the project increases with $\beta_{\mathrm{p}}$. Finally, when $\beta_{\mathrm{p}}=1$, expression (33) has a simple interpretation: the social value of the project is the sum, over all demand states, of private surplus $v-I$, augmented by the fact that this surplus allows the government to reduce distortionary taxation, plus the value of the externality.

A low demand project In this case $I>\gamma v_{\max }, S^{*}(\nu)+R^{*}(v)=I$ and $R^{*}(v)=\gamma \nu$ for all states $v$. Hence, after some algebraic manipulation,

$$
S V=\int\left\{\left[\lambda \beta_{\mathrm{p}}+1\right] \nu-(1+\lambda) I-(1+\lambda)(1+\zeta)(I-\gamma \nu)\right\} f(\nu) d \nu+\mathscr{E} \geq 0 .
$$

If, in addition, $\gamma=1$ (which implies $\beta_{\mathrm{p}}=1$ ), this condition becomes

$$
S V=\int[(1+\lambda)(\nu-I)-(1+\lambda) \zeta(I-\gamma \nu)] f(\nu) d \nu+\mathscr{E} \geq 0
$$

This expression is the same as (33), but for the fact that now the project must bear an additional cost in states where subsidies are paid: $(1+\lambda) \zeta(I-\gamma \nu)$. Moreover, since

$$
S^{*}(\nu)=I-R^{*}(\nu)=I-\gamma \nu
$$

the social value of the project is (locally) increasing in $\gamma$ when $\gamma<\beta_{\mathrm{p}}$. 
An intermediate demand project In this case, $R^{*}(\nu)=M>I$, and $S^{*}(\nu)=0$ in high demand states. Hence, social surplus in such a state $s$ is

$$
S V(s)=\left[\lambda \beta_{\mathrm{p}}+1\right] v+(1+\lambda-\alpha) M-\alpha I+\mathscr{E}
$$

In intermediate demand states $R^{*}(\nu)=\gamma \nu$ and $S^{*}(\nu)=0$. Hence, social surplus is SV(s) $=$

$$
\left[\lambda \beta_{\mathrm{p}}+1\right] v-(1+\lambda) \gamma v+\alpha(\gamma \nu-I)+\mathscr{E}
$$

In low demand states $R^{*}(v)=\gamma \nu$ and $\gamma \nu+S^{*}(v)=m<I$. Hence, social surplus is $\mathrm{SV}(\mathrm{s})=$

$$
\left[\lambda \beta_{\mathrm{p}}+1\right] v-(1+\lambda) \zeta \gamma v-(1+\lambda)(1+\zeta) m+\alpha(m-I)+\mathscr{E}
$$

This implies that the condition is

$$
\begin{aligned}
S V=\int\left\{\lambda \beta_{\mathrm{p}} v+v-\alpha I\right\} f(v) d v & -(1+\lambda-\alpha)\left[M(1-F(M))+\int_{m}^{M} \gamma v f(v) d v+m F(m)\right] \\
& -(1+\lambda) \zeta \int_{\nu_{\min }}^{m}(m-\gamma v) f(v) d v+\mathscr{E} \geq 0 .
\end{aligned}
$$

\section{B When is a PPP better than conventional unbundled pro- vision?}

\section{B.1 Modeling the differences between conventional provision and PPPs}

The literature has identified several reasons for the differences between PPPs and conventional provision.

1. As we point out, government spending may be inefficient in general, in addition to the costs created by distortionary taxation. This is captured by the parameter $\zeta$ in our model.

2. Hart (2003) suggested that bundling may stimulate cost savings, because design is adapted to lower operation costs. The point is that the procurement choice by itself may affect costs. In our framework this can be modeled by assuming that under conventional (unbundled) provision total costs are $\sigma I$ instead of $I$. If the public sector is more efficient in building a particular project, then $\sigma<1$, while $\sigma>1$ if the private sector is more efficient.

3. Hart (2003) has also pointed out that the private concessionaire may have incentives to save at the expense of quality of service. I other projects, a private concessionaire may responde better better to the needs of users. We may assume that user willingness to pay is $\eta v$ with conventional provision and $v$ with a private concessionaire. 
If the public sector is more effective in creating welfare for consumers, then $\eta>1$, while $\eta<1$ if the private sector is more effective.

4. The capacity to charge users of the infrastructure may depend on the way the infrastructure is provided. We introduce a parameter $\beta_{\text {tr }}$ that captures the fraction of user's willingness to pay that can be effectively charged under conventional provision.

Assumption $1 \beta_{\mathrm{tr}} \leq \beta_{\mathrm{p}}$.

It follows that with conventional provision, consumer surplus is

$$
\mathrm{CS}(v)=\left[\lambda \beta_{\mathrm{tr}}+\eta\right] v-(1+\lambda)(1+\zeta) \sigma I+\mathscr{E} \text {. }
$$

Social surplus is thus

$$
\int\left\{\left[\lambda \beta_{\mathrm{tr}}+\eta\right] \nu-(1+\lambda)(1+\zeta) \sigma I\right\} f(\nu) d \nu+\mathscr{E}
$$

\section{B.2 PPPs vs. conventional provision}

Substracting (34) from (32) above, yields that a PPP is better than conventional provision if

$$
\begin{aligned}
\int\left\{\lambda\left(\beta_{\mathrm{p}}-\beta_{\mathrm{tr}}\right) \nu-\left[(1+\lambda-\alpha) R^{*}(\nu)+[(1+\lambda)(1+\zeta)-\alpha] S^{*}(\nu)\right]\right\} f(\nu) d v \\
+\int\{(1-\eta) v+[(1+\lambda)(1+\zeta) \sigma-\alpha] I\} f(v) d v \geq 0 .
\end{aligned}
$$

The first integral contains the terms that are central to our paper. $\lambda\left(\beta_{\mathrm{p}}-\beta_{\mathrm{tr}}\right) v$ indicates that one advantage of PPPs is that they substitute for distortionary taxation. If PPP's enhance the ability to charge users, this is a point in their favor over conventional provision. This term disappears if $\beta_{\mathrm{p}}=\beta_{\mathrm{tr}}=1$. The second term, $(1+\lambda-\alpha) R^{*}(\nu)+[(1+\lambda)(1+\zeta)-\alpha] S^{*}(\nu)$, explains the structure of the optimal contract. As a means of financing the project, subsidies are more expensive than project revenues, which is captured by $(1+\lambda)(1+\zeta)-\alpha>$ $1+\lambda-\alpha$.

The second integral contains two terms identified in the literature (in particular, Hart (2003)), as potential advantages or disadvantages of PPPs. The first term, $(1-\eta) \nu$, indicates that gross consumer surplus may increase or decrease with a PPP, depending on the sign of $1-\eta$, i.e., on whether the concessionaire is better at providing the service to users. The second term, $[(1+\lambda)(1+\zeta) \sigma-\alpha] I$, shows that PPP may reduce the costs of provision. One possible reason is that subsidy spending is by itself wasteful; this is captured with $\zeta>0$. The other reason is that a PPP structure by itself may alter incentives in such a way that the direct cost of the project may be smaller, for example, because bundling stimulates better design or by reducing total costs during the duration of the concession. This is captured by the term $\sigma>1$.

We can now develop specific expressions for each type of project. 
A high demand project In this case $I \leq \gamma \nu_{\min }, R^{*}(\nu)=I$ and $S^{*}(\nu)=0$ for all $\nu$. Thus, substituting into (35) and rearranging yields that a PPP is better if

$$
\int\left[\lambda\left(\beta_{\mathrm{p}}-\beta_{\mathrm{tr}}\right) \nu\right] f(\nu) d v+\int\{(1-\eta) v+(1+\lambda)[(1+\zeta) \sigma-1] I\} f(\nu) d v \geq 0
$$

Result 1 With a high demand project it is irrelevant whether productive efficiencies are achieved in $\zeta$ or $\sigma$. Moreover, whether a PPP beats conventional provision does not depend on $\alpha$.

A low demand project In this case $I>\gamma v_{\max }, S^{*}(v)+R^{*}(v)=I$ and $R^{*}(v)=\gamma v$ for all states $v$. Substituting into (35) and rearranging yields that a PPP is better if

$$
\int\left[\lambda\left(\beta_{\mathrm{p}}-\beta_{\mathrm{tr}}\right) v-(1+\lambda) \zeta(I-\gamma v)\right] f(\nu) d v+\int\{(1-\eta) v+(1+\lambda)[(1+\zeta) \sigma-1] I\} f(\nu) d v \geq 0
$$

An intermediate demand project In this case, evaluation of (35) in the different cases and rearranging yields that a PPP is preferable if

$$
\begin{aligned}
\int\left\{\lambda\left(\beta_{\mathrm{p}}-\beta_{\mathrm{tr}}\right) \nu+\right. & (1-\eta) \nu+[(1+\lambda)(1+\zeta) \sigma-\alpha] I\} f(\nu) d v \\
-(1+\lambda-\alpha)\left[M(1-F(M))+\int_{m}^{M} \gamma \nu f(\nu) d v+m F(m)\right] & -(1+\lambda) \zeta \int_{v_{\min }}^{m}(m-\gamma \nu) f(\nu) d v \geq 0 .
\end{aligned}
$$

\section{A microfoundation for $\zeta$}

In the text we distinguish between the social costs of taxation (efficiency on the revenue side), which we capture with $\lambda$, and the relative efficiency with which the public sector spends, which we capture with $\zeta$ (efficiency on the expenditure side). ${ }^{69}$ This distinction, while necessary to explore the place of PPPs in the public budget, is unconventional, as the literature typically models only the social cost of taxation. In this appendix we derive $\lambda$ and $\zeta$ as part of the optimization of the public sector, thus providing a microfoundation for the value of $\zeta$. We show that, at the margin, the product $(1+\lambda)(1+\zeta)$, which measures the marginal cost of subsidizing the concessionaire, also equals the social benefit of spending one additional dollar in the marginal public project. Moreover, we also show that $\zeta$ is specific to the agency or ministry responsible for the infrastructure project.

\footnotetext{
${ }^{69}$ We are aware that public spending may be inefficient due to failures of project selection. We do not consider that problem here.
} 


\section{C.1 Model}

Consider a benevolent planner who must choose the aggregate tax burden, $T$, and then allocate spending between government agencies $i=1,2, \ldots, n$. What is the optimal size of each government agency and of the public sector at large?

On the revenue side, let $T+\Lambda(T) \geq T$ be the total cost to taxpayers of paying $T$ in taxes. We assume that $\Lambda: R_{+} \rightarrow R_{+}$, with $\Lambda^{\prime} \equiv \lambda \geq 0$ and $\lambda^{\prime}>0$. As usual, $1+\lambda$ is the marginal cost of public funds.

Consider now the spending side. The comparison between the traditional model and PPPs is, at its root, a comparison of relative efficiency. For this reason, a useful benchmark on the cost side is the private sector's efficiency in spending. ${ }^{70}$

We model this by assuming that one dollar of private spending generates one dollar of "useful" spending. By contrast, achieving $G_{i}$ dollars of useful spending in government agency $i$ costs $G_{i}+Z_{i}\left(G_{i}\right)$ dollars. We assume that $Z_{i}: \mathrm{R}_{+} \rightarrow \mathrm{R}_{+}$, with $Z_{i}(0)=0, Z_{i}^{\prime} \equiv \zeta_{i} \gtreqless 0$ and $\zeta_{i}^{\prime} \geq 0$, with strict inequality if $G_{i} \geq \bar{G}_{i}$. Note that $\zeta_{i}$ is a measure of the relative marginal efficiency of spending one dollar in government agency $i$. In principle, at a given level of spending the government agency can be more, equally or less efficient than the private sector. Eventually, the optimal size of government agency $i$ must be bounded, because $\zeta_{i}^{\prime}>0$.

The following cases are of particular interest. If $\zeta_{i}\left(G_{i}\right)>0$ for all $G_{i} \geq 0$, then the government agency always spends more inefficiently than the private sector: it needs $1+\zeta_{i}\left(G_{i}\right)>1$ dollars to increase useful spending by one dollar. Next, if $\zeta_{i}=0$ and $\zeta_{i}^{\prime}=0$ for $G_{i} \in\left(0, \bar{G}_{i}\right)$ then $Z_{i}\left(G_{i}\right)>0$ for $G_{i} \in\left[0, \bar{G}_{i}\right)$ and government agency $i$ spends as efficiently as the private sector. Finally, assume that $0<1+\zeta_{i}(0)<1$ and $\zeta_{i}^{\prime} \geq 0$ for all $G_{i}$. Then there exists an interval $\left[0, \bar{G}_{i}\right]$ such that $\zeta_{i}\left(G_{i}\right)<0$. In that interval the government agency is a better spender than the private sector, as it needs less than one dollar of spending to achieve a dollar of useful spending.

Consider now government agency $i$ 's portfolio of projects, which can be ordered from highest to lowest return per dollar of useful spending. This portfolio can be characterized by $\mathscr{S}_{i}\left(G_{i}\right)$, the surplus created if government agency $i$ spends $G_{i}$ dollars in its best projects. We assume that $\mathscr{S}_{i}: \mathrm{R}_{+} \rightarrow \mathrm{R}_{+}$, with $\mathscr{S}_{i}(0)=0, \mathscr{S}_{i}^{\prime} \geq 0, \lim _{G_{i} \rightarrow 0} \mathscr{S}_{i}^{\prime}\left(G_{i}\right)=\infty$ and $\mathscr{S}_{i}^{\prime \prime}<0$. Note that $\mathscr{S}_{i}^{\prime}\left(G_{i}\right)$ is the surplus created by the marginal project when $Z_{i}\left(G_{i}\right)$ dollars have been spent in government agency $i$.

To keep things simple, we are assuming that there exists a portfolio of projects that attains a larger surplus if executed through the public sector-thus $\lim _{G_{i} \rightarrow 0} \mathscr{S}_{i}^{\prime}\left(G_{i}\right)=\infty$. Note that social surplus can be written as

$$
\mathscr{N}_{i}\left(G_{i}\right) \equiv \mathscr{S}_{i}\left(G_{i}\right)-Z_{i}\left(G_{i}\right),
$$

thus directly subtracting from the government agency's creation of value the net inefficiency of its spending. While this would simplify the presentation, it obscures the fact that

\footnotetext{
${ }^{70}$ Recall here that we have explicitly excluded the efficiency benefits due to productive bundling of construction, operations and maintenance, which represent an additional motive for PPP's.
} 
one advantage of PPPs is that the private sector may spend more efficiently than the ministry. Finally, we note that the government's budget constraint is

$$
T=\sum_{i=1}^{n} G_{i}+Z_{i}\left(G_{i}\right)
$$

\section{C.2 An optimal fiscal policy}

The planner chooses $T$ and $\left(G_{i}\right)_{i=1}^{n}$ to maximize the following Lagrangian:

$$
\mathscr{L}=\sum_{i=1}^{n}\left[\mathscr{S}_{i}\left(G_{i}\right)-G_{i}-Z_{i}\left(G_{i}\right)\right]-\Lambda(T)-\mu\left[\sum_{i=1}^{n} G_{i}+Z_{i}\left(G_{i}\right)-T\right] .
$$

The first term is the net social surplus created by each government agency. The second term is the net cost imposed on society by taxation. The last term is the government's budget constraint.

The first order conditions are

$$
\frac{\partial \mathscr{L}}{\partial G_{i}}=\mathscr{S}_{i}^{\prime}-\left(1+\zeta_{i}\right)-\mu\left(1+\zeta_{i}\right)=0,
$$

and

$$
\frac{\partial \mathscr{L}}{\partial T_{i}}=-\lambda+\mu=0
$$

Condition (37) states the obvious result: at the margin, the shadow value of one dollar of additional taxes equals the marginal cost of public funds. Next, substituting (38) into (37) and rearranging yields that

$$
\mathscr{S}_{i}^{\prime}=(1+\lambda)\left(1+\zeta_{i}\right)
$$

at the optimum. That is, the marginal surplus created by one dollar of spending by government agency $i$ equals the marginal cost of public funds times the relative efficiency of spending money in government agency $i$.

Microfoundation for the equilibrium value of $\zeta_{i} \quad$ Condition (39) provides a microfoundation for the value of $\zeta_{i}$. At the optimum, the shadow cost of subsidizing the PPP by one additional dollar can be assessed from two different perspectives. On the one hand, one could increase the aggregate tax burden by $1+\zeta_{i}$, which would cost society $(1+\lambda)\left(1+\zeta_{i}\right)$ dollars in total. On the other hand, given the amount of government revenue from taxes (at a marginal cost of $1+\lambda$ per dollar of revenue) government agency $i$ could reduce its spending by $1+\zeta_{i}$ dollars, which would cost society $\mathscr{S}_{i}^{\prime}$ in foregone social surplus. If the government is running an optimal fiscal policy, $\mathscr{S}_{i}^{\prime}=(1+\lambda)\left(1+\zeta_{i}\right)$-both quantities are exactly the same.

PPPs and the optimal size of a government agency $i$ The marginal cost of spending $1+\zeta_{i}$ determines the optimal size of the government agency $i$, as can be observed in Figure 4 . On the horizontal axis we measure useful spending $G_{i}$. On the vertical axis we measure the marginal cost and benefits of spending in government agency $i$. 
Figure 4: Determination of the optimal size of a government agency

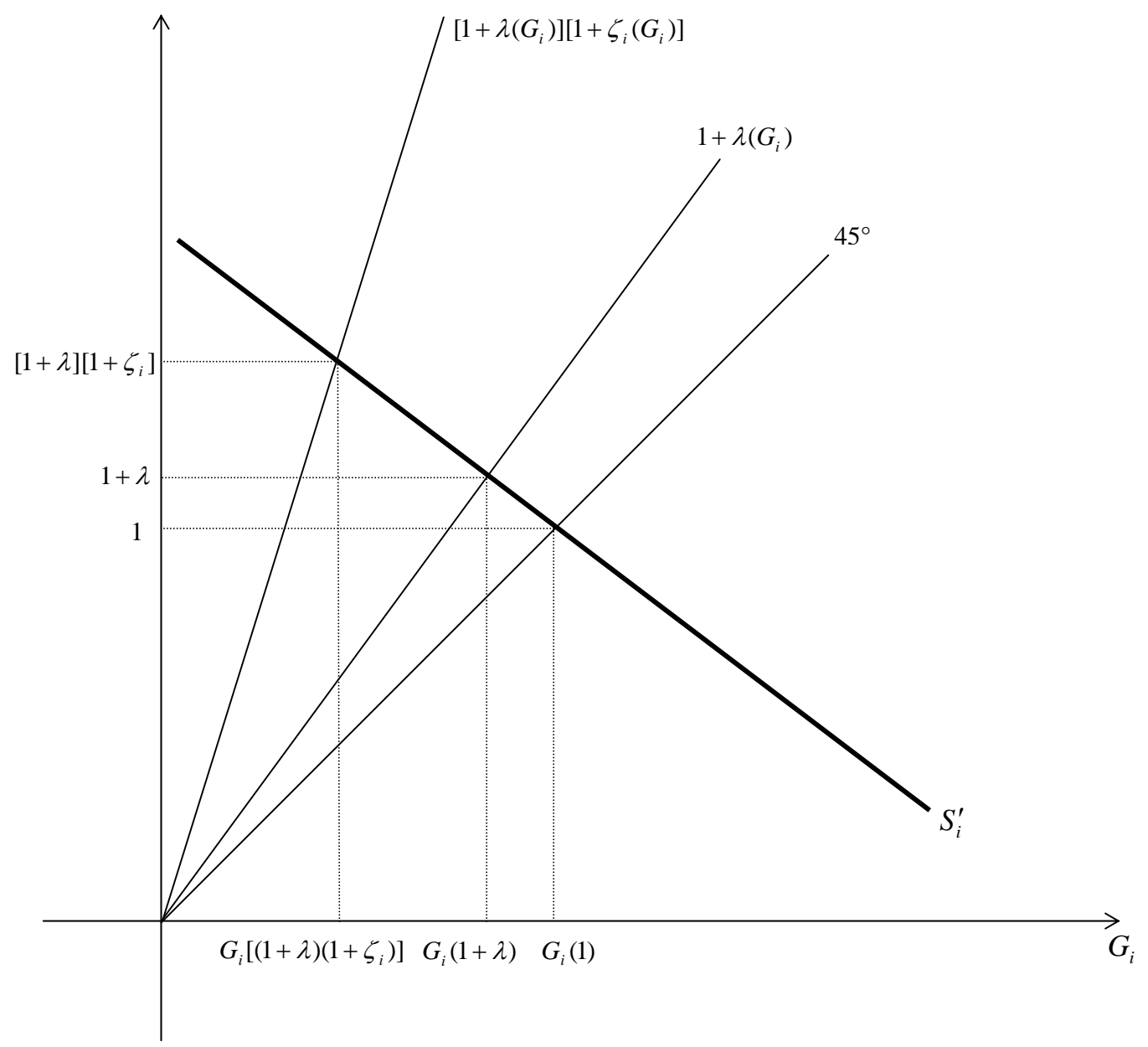


Note that the optimal size of government agency $i$ depends on $\mathscr{S}_{i}, \zeta_{i}$ and $\lambda$. If taxation is non-distortionary $(\lambda=0)$ and ministry $i$ spends as efficiently as the private sector, then the total cost of spending $G_{i}$ in government agency $i$ equals $G_{i}$. Thus, the marginal-costof-spending schedule is the $45^{\circ}$ line, at the optimum $\mathscr{S}_{i}^{\prime}=1$ and total spending equals $G_{i}(1)$.

Because taxation is distortionary, however, even if ministry $i$ is as efficient as the private sector when spending, the cost of spending an additional dollar by government is $1+\lambda>1$, because to do so the government must impose distortionary taxes. Thus, the marginalcost-of-spending schedule is above the $45^{\circ}$ line. At the optimum $\mathscr{S}_{i}^{\prime}=1+\lambda>1$ and $G_{i}(1+$ $\lambda)<G_{i}(1)$.

Now introduce the government agency's relative efficiency of spending into the picture and assume $\zeta_{i}\left(G_{i}\right)>0$ for all $G_{i} \geq 0$. The marginal-cost-of-spending schedule is even further above the $45^{\circ}$ line. Consequently, at the optimum $\mathscr{S}_{i}^{\prime}=(1+\lambda)\left(1+\zeta_{i}\right)$ and $G_{i}((1+\lambda)(1+$ $\left.\zeta_{i}\right)<G_{i}(1+\lambda)<G_{i}(1)$.

Consider, finally, the place of a small PPP in government agency $i$. If the PPP does not require any public subsidy, then $1+\lambda$ is the proper shadow price of the foregone revenue that the concessionaire receives. Thus, all projects such that $\mathscr{S}_{i}^{\prime}\left(G_{i}\right) \in\left[1+\lambda,(1+\lambda)\left(1+\zeta_{i}\right)\right]$ in the government agency's pecking order should be undertaken with a PPP, but not with the traditional model.

On the other hand, if the PPP does require subsidies at the margin, the rule is to minimize them. Revenues from the project should go to the concessionaire, and only the deficit should come from subsidies. It follows that some projects such that $\mathscr{S}_{i}^{\prime}\left(G_{i}\right) \in(1+\lambda,(1+$ $\left.\lambda)\left(1+\zeta_{i}\right)\right)$ will be undertaken using a PPP, but will not be undertaken using the traditional model.

PPPs and the relative size of government agencies Finally, we can derive a rule for the allocation of spending across government agencies. Note that at the optimum

$$
\frac{\mathscr{S}_{i}^{\prime}}{1+\zeta_{i}}=1+\lambda=\frac{\mathscr{S}_{j}^{\prime}}{1+\zeta_{j}} .
$$

Thus the marginal surplus created by spending an additional dollar in government agency $i$ adjusted by $i$ 's relative marginal efficiency equals the value of spending one additional dollar in government agency $j$ adjusted by $j$ 's relative marginal efficiency.

Consider now a PPP that creates exactly the same surplus in any government agency. Because $\zeta_{i}$ will in general differ across government agencies, some PPPs will be undertaken if located in some government agencies, but not if they are located in others. ${ }^{71}$

\footnotetext{
${ }^{71} \mathrm{~A}$ similar analysis can be done with government agencies across countries: a project may be undertaken via PPP's by a given government agency in country A, but not by the analogous government agency in country $\mathrm{B}$, due to a different value of $\zeta_{i}$, even if the cost of taxation is the same.
} 


\section{Proofs of Propositions}

\section{D.1 Proof of Proposition 1}

Since $u$ is concave, applying Jensen's inequality to the concessionaire's participation constraint leads to

$$
u\left(\int[R(v)+S(v)] f(v) d v-I\right) \geq \int u(R(v)+S(v)-I) f(v) d v=u(0) .
$$

And since $u$ is strictly increasing, the above inequality implies that

$$
\mathrm{E}[R]+\mathrm{E}[S] \geq I,
$$

where $\mathrm{E}[R]=\int R(v) f(v) d v$ denotes the expected revenue before demand is realized and $\mathrm{E}[\mathrm{S}]$ denotes expected government expenditure on subsidies.

It follows that if the solution to

$$
\begin{gathered}
\min _{R \geq 0, S \geq 0}(1+\lambda-\alpha) \mathrm{E}[R]+[(1+\lambda)(1+\zeta)-\alpha] \mathrm{E}[S] \\
\text { s.t. } \mathrm{E}[R]+\mathrm{E}[S] \geq I,
\end{gathered}
$$

satisfies (5b)-(5d), then it solves program (5a)-(5d) as well.

Hence, if $\zeta=0$, any combination of revenue and subsidy schedules that satisfies (5c), (5d), and $R(v)+S(v)=I$ for all $v$, solves the planner's problem.

\section{D.2 Proof of Proposition 4}

Having established the form of the optimal contract, the planner's problem is equivalent to finding $m$ and $M$ that minimize

$$
M(1-F(M))+\int_{0}^{M} v f(v) d v+(1+\bar{\zeta}) F(m) \int_{0}^{m}(m-v) f(v) d v
$$

subject to the concessionaire's participation constraint (11). Noting that (11) implicitly defines $M$ as a function of $m$, we have that:

$$
M^{\prime}(m)=-\frac{F(m) u^{\prime}(m-I)}{(1-F(M)) u^{\prime}(M-I)} .
$$

A similar calculation shows that the rate at which $M$ and $m$ have to change to keep the objective function (41) unchanged is given by

$$
M^{\prime}(m)=-\frac{(1+\bar{\zeta}) F(m)}{1-F(M)} .
$$


Equating (42) and (43) for $M^{\prime}(m)$ leads to (12) and completes the proof. ${ }^{72}$

\section{D.3 Proof of Proposition 5}

With the assumptions and notation introduced in the main text we prove that:

$$
\begin{aligned}
M^{\prime}(\zeta) & =\frac{(1+\lambda) F(m)}{[(1+\lambda)(1+\zeta)-\alpha] F(m) \operatorname{CARA}(M-I)+(1+\lambda-\alpha)(1-F(M)) \operatorname{CARA}(m-I)}, \\
m^{\prime}(\zeta) & =-\frac{(1+\lambda)(1+\lambda-\alpha)(1-F(M))}{[(1+\lambda)(1+\zeta)-\alpha]\{[(1+\lambda)(1+\zeta)-\alpha] F(m) \operatorname{CARA}(M-I)+(1+\lambda-\alpha)(1-F(M)) \operatorname{CARA}(m-I)\}}, \\
M^{\prime}(\zeta)-m^{\prime}(\zeta) & =\frac{(1+\lambda)[[(1+\lambda)(1+\zeta)-\alpha] F(m)+(1+\lambda-\alpha)(1-F(M))]}{[(1+\lambda)(1+\zeta)-\alpha]\{[(1+\lambda)(1+\zeta)-\alpha] F(m) \operatorname{CARA}(M-I)+(1+\lambda-\alpha)(1-F(M)) \operatorname{CARA}(m-I)\}} .
\end{aligned}
$$

It follows that risk borne by the concessionaire increases with the social cost of subsidies, $1+\zeta$. Furthermore, $[(1+\lambda)(1+\zeta)-\alpha]\left(M^{\prime}(\zeta)-m^{\prime}(\zeta)\right) /(1+\lambda)$ takes a value between $1 / \operatorname{CARA}(m-I)$ and $1 / \operatorname{CARA}(M-I)$.

We define $C(I) \equiv \operatorname{CARA}(M-I) / \operatorname{CARA}(m-I)$ and also show that:

$$
\begin{aligned}
m^{\prime}(I) & =1+\frac{(1+\bar{\zeta}) C(I) \int_{m}^{M} u^{\prime}(\nu-I) f(\nu) d v}{[(1+\bar{\zeta}) C(I) F(m)+1-F(M)] u^{\prime}(m-I)}, \\
M^{\prime}(I) & =1+\frac{\int_{m}^{M} u^{\prime}(\nu-I) f(\nu) d v}{[(1+\zeta) C(I) F(m)+1-F(M)] u^{\prime}(M-I)}, \\
M^{\prime}(I)-m^{\prime}(I) & =(1+\bar{\zeta})(1-C(I)) \frac{\int_{m}^{M} u^{\prime}(\nu-I) f(\nu) d v}{[(1+\bar{\zeta}) C(I) F(m)+1-F(M)] u^{\prime}(m-I)} .
\end{aligned}
$$

It follows that $m$ and $M$ grow faster than $I$. Also, for a concessionaire with decreasing absolute risk aversion, the wedge between $M$ and $m$ increases with $I$, while it does not depend on $I$ for a concessionaire with constant absolute risk aversion.

Proof Implicit differentiation of (12) with respect to $\zeta$ and a bit of algebra leads to:

$$
M^{\prime}(\zeta)=\frac{1+\lambda}{[(1+\lambda)(1+\zeta)-\alpha] \operatorname{CARA}(M-I)}+\frac{\operatorname{CARA}(m-I)}{\operatorname{CARA}(M-I)} m^{\prime}(\zeta) .
$$

Implicitly differentiating (11) with respect to $\bar{\zeta}$ leads to:

$$
M^{\prime}(\zeta)=-\frac{[(1+\lambda)(1+\zeta)-\alpha] F(m)}{(1+\lambda-\alpha)(1-F(M)))} m^{\prime}(\zeta)
$$

Both expressions above lead to the comparative statics results for $\bar{\zeta}$.

Implicit differentiation of (12) with respect to $I$ leads to:

$$
\frac{m^{\prime}(I)-1}{M^{\prime}(I)-1}=(1+\bar{\zeta}) C(I) .
$$

\footnotetext{
${ }^{72}$ The above proof assumes that $F(m)>0$ and $F(M)<1$. Footnote 40 outlines the proof when this is not the case.
} 
Implicit differentiation of (11) with respect to $I$ leads to:

$$
F(m) u^{\prime}(m-I)\left[m^{\prime}(I)-1\right]+\int_{m}^{M} u^{\prime}(\nu-I) f(v) d v+(1-F(M)) u^{\prime}(M-I)\left[M^{\prime}(I)-1\right]=0 .
$$

The three comparative statics expressions in I now follow easily.

\section{D.4 Proof of Proposition 9}

Proof Part (i) It follows immediately from the planner's objective function that $p^{G}(\theta)=$ $p^{*}(1+\lambda, \theta)$ when $\gamma<1$, that is, when the contract length is finite.

To derive the expressions for $p^{C}(\theta)$, consider first the case where the contract length is finite. We fix the concessionaire's profits, and choose the price that maximizes the planner's welfare, that is, we solve:

$$
\begin{aligned}
\max _{p, \gamma} & \gamma H(p, \alpha)+(1-\gamma) H^{*}(1+\lambda) \\
\text { s.t. } & \gamma \Pi(p)=K,
\end{aligned}
$$

where we have dropped $\theta$ from our notation, $H^{*}(1+\lambda) \equiv H\left(p^{*}(1+\lambda)\right)$ and $p$ stands for $p^{C}$. Using the constraint to get rid of $\gamma$ in the objective function leads to the following equivalent problem:

$$
\max _{p} \frac{\operatorname{CS}(p)-H^{*}(1+\lambda)}{\Pi(p)} .
$$

The corresponding first order condition leads to:

$$
H^{*}(1+\lambda)=\operatorname{CS}(p)-\frac{\mathrm{CS}^{\prime}(p)}{\Pi^{\prime}(p)} \Pi(p)
$$

and it follows from (16) that $p=p^{*}(1+\lambda)$ is optimal in this case.

Part (ii) Next we consider the case where $S>0$ and maximize the planner's objective function over $p$ and $S$, keeping fixed the concessionaire's total profits:

$$
\begin{array}{cl}
\max _{p, S} & H(p, \alpha)-[(1+\lambda)(1+\zeta)-\alpha] S \\
\text { s.t. } & \Pi(p)+S=K .
\end{array}
$$

This time we use the constraint to get rid of $S$ in the objective function, which leads to:

$$
\max _{p} H(p, \alpha)+[(1+\lambda)(1+\zeta)-\alpha] \Pi(p)
$$

which, by the definition of $H$, is equivalent to choosing the user fee that maximizes $H(p,(1+$ $\lambda)(1+\zeta))$. It follows that $p^{C}=p^{*}((1+\lambda)(1+\zeta))$ in this case. 
Part (iii) We consider two intermediate demand states, $\theta_{1}$ and $\theta_{2}$, and find the optimal price in each state subject to a fixed expected utility for the concessionaire. That is, we solve:

$$
\begin{array}{rl}
\max _{p_{1}, p_{2}} & H\left(p_{1}, \alpha, \theta_{1}\right) f\left(\theta_{1}\right)+H\left(p_{2}, \alpha, \theta_{2}\right) f\left(\theta_{2}\right) \\
\text { s.t. } & u\left(\Pi\left(p_{1}, \theta\right)-I\right) f\left(\theta_{1}\right)+u\left(\Pi\left(p_{2}, \theta\right)-I\right) f\left(\theta_{2}\right)=K .
\end{array}
$$

The Lagrangian for this problem is

$$
\mathscr{L}\left(p_{1}, p_{2}\right)=H\left(p_{1}, \alpha, \theta_{1}\right) f\left(\theta_{1}\right)+H\left(p_{2}, \alpha, \theta_{2}\right) f\left(\theta_{2}\right)+\mu\left[u_{1}^{\prime} f\left(\theta_{1}\right)+u_{2}^{\prime} f\left(\theta_{2}\right)\right],
$$

where $u_{i}^{\prime}=u\left(\Pi\left(p_{i}, v\right)-I\right), i=1,2$, and $\mu$ denotes the multiplier for the concessionaire's participation constraint.

Using the first order conditions in $p_{1}$ and $p_{2}$ to get rid of $\mu$ then leads to:

$$
\frac{u_{1}^{\prime}}{u_{2}^{\prime}}=\frac{\frac{\mathrm{CS}_{p}\left(p_{1}, \theta\right)}{\Pi_{p}\left(p_{1}, \theta_{1}\right)}+\alpha}{\frac{\mathrm{CS}_{p}\left(p_{2}, \theta_{2}\right)}{\Pi_{p}\left(p_{1}, \theta_{1}\right)}+\alpha}
$$

Define $\eta_{1}$ and $\eta_{2}$ via $p_{1}=p^{*}\left(\eta_{1}, \theta_{1}\right)$ and $p_{2}=p^{*}\left(\eta_{2}, \theta_{2}\right)$. Since $\theta_{1}$ and $\theta_{2}$ are intermediate demand states and $\Pi\left(p^{*}(\eta), \theta\right)$ is increasing in $\eta$, we have that $\eta_{i} \in(1+\lambda,(1+\lambda)(1+\zeta))$, $i=1,2$. The above expression combined with (16) implies that:

$$
\frac{u_{1}^{\prime}}{u_{2}^{\prime}}=\frac{\eta_{1}-\alpha}{\eta_{2}-\alpha} .
$$

A similar argument, with an intermediate and a low (high) demand state instead of two intermediate states, leads to the second (third) equality in (20).

\section{D.5 Proof of Proposition 10}

We use Figure 2 to extend (41) and (42) to the more general setting considered here and in this way prove (22). We show that the planner substitutes $m$ and $M$ at a rate:

$$
M^{\prime}(m)=-\frac{(1+\bar{\zeta}) F_{(1+\lambda)(1+\zeta)}(m)}{1-F_{1+\lambda}(M)},
$$

while the rate at which $m$ and $M$ are substituted along the concessionaire's participation constraint satisfies:

$$
M^{\prime}(m)=-\frac{F_{(1+\lambda)(1+\zeta)}(m) u^{\prime}(m-I)}{\left(1-F_{1+\lambda}(M)\right) u^{\prime}(M-I)} .
$$

Equating both rates of substitution leads to (22).

Consider the impact on the concessionaire's participation constraint of an increase of 
$m$ by $\Delta m$. Demand states than originally enjoyed a minimum revenue guarantee of $m$ see this guarantee increase by $\Delta m$, thereby increasing the concessionaire's expected utility by $F_{(1+\lambda)(1+\zeta)}(m) u^{\prime}(m-I) \Delta m$. We also have a small fraction of states-those with $v_{(1+\lambda)(1+\zeta)} \in$ $[m, m+\Delta m]$ - that now have a guarantee and did not have one before. And the user-fee in these states is somewhat smaller once they have a minimum revenue guarantee. In any case, the contribution of these marginal states to the concessionaire's expected utility is of second order in $\Delta m$ and can therefore be ignored.

A similar argument shows that a decrease of $M$ by $\Delta M$ leads to a decrease of the concessionaire's expected utility of $\left(1-F_{1+\lambda}(M) u^{\prime}(M-I) \Delta M\right.$, where again we ignore higher order terms in $\Delta M$. Equating to zero the expected utility change associated with an increase in $m$ and a decrease of $M$ leads to (45).

To derive (44) we first use our two-threshold characterization of the optimal contract to simplify the planner's objective function (17a). In high demand states we have $\gamma \Pi\left(p^{*}(1+\right.$ $\lambda))=M$ and therefore

$$
[\alpha \gamma+(1+\lambda)(1-\gamma)] \Pi=(1+\lambda) \Pi-(1+\lambda-\alpha) M
$$

We use this expression to get rid of $\gamma$ in the expression for welfare in high demand states:

$$
\mathbb{W}_{\text {high }}=\operatorname{CS}\left(p^{*}(1+\lambda)\right)+\alpha M+(1+\lambda)\left(\Pi\left(p^{*}(1+\lambda)\right)-M\right) .
$$

In low demand states we have $\Pi+S=m$, which allows us to get rid of $S$ in the planner's welfare function for these states:

$$
\mathscr{W}_{\text {low }}=\operatorname{CS}\left(p^{*}((1+\lambda)(1+\zeta))\right)+\alpha m+(1+\lambda)(1+\zeta)\left(\Pi\left(p^{*}((1+\lambda)(1+\zeta))\right)-m\right)
$$

Finally, in intermediate demand states we have:

$$
\mathbb{W}_{\text {int }}=\operatorname{CS}\left(p^{*}(\eta)\right)+\alpha \Pi\left(p^{*}(\eta)\right)
$$

with $\eta \in(1+\lambda,(1+\lambda)(1+\zeta))$ determined from (20).

Consider next the effect on total welfare of an increase of $\Delta m$ in $m$ and a decrease of $\Delta M$ in $M$. Comparing (46)-(48) it is clear that the change in welfare due to marginal firmsthose close to $m$ or $M$-is second order, since $\eta \approx(1+\lambda)(1+\zeta)$ for firms with $w_{(1+\lambda)(1+\zeta)}$ close to $m$ and $\eta \approx 1+\lambda$ for firms with $w_{1+\lambda}$ close to $M$. It follows that, as in the previous case, the first order aggregate change in welfare is due to inframarginal low demand states and inframarginal high demand states. The subsidy paid out in the former states increases significantly, leading to a welfare reduction of $[(1+\lambda)(1+\zeta)-\alpha] F_{(1+\lambda)(1+\zeta)}(m) \Delta m$. And user fees freed up by the decrease in $M$ allow the government to reduce distortions elsewhere in the economy, increasing welfare by $(1+\lambda-\alpha)\left(1-F_{1+\lambda}(M)\right) \Delta M$. Equating to zero the total change in welfare leads to (44) and completes the proof. 


\section{E Moral hazard and a single-crossing property}

\section{Proof of Proposition 11}

A straightforward adaptation of the proof of standard moral hazard results can be used to prove that $\mathscr{T}(v)$ is strictly increasing. For example, following the argument in the proof of Proposition 5.2 in Laffont and Martimort (2002) leads to

$$
\begin{aligned}
\mu & =(1+\lambda-\alpha) \mathrm{E}\left[\frac{1}{u^{\prime}(\mathscr{T}(v)-I)}\right] \\
\tau & =\frac{1+\lambda-\alpha}{k} \operatorname{Cov}\left(\frac{1}{u^{\prime}(\mathscr{T}(v)-I)}, u(\mathscr{T}(v)-I)\right) .
\end{aligned}
$$

$>$ From $u^{\prime}>0$ it then follows that $\mu>0$, while the fact that $u$ and $u^{\prime}$ covary in opposite directions implies that $\tau>0$. The MLRP and (26) then imply that $\mathscr{T}(v)$ is strictly increasing in $v$.

The fact that $\mathscr{T}$ is strictly increasing in $v$ does not imply that it crosses the 45 -degree line only once and from above, thereby ensuring the existence of $M$ such that states with $v<M$ are low demand (they require a subsidy) while state with $v>M$ are high demand (finite term). This requires that the function $\mathscr{G}(\nu, \epsilon)$ satisfies a single-crossing property. We consider this property below, working with the more general case where $\zeta>0$.

\section{Problem Set Up}

We partition demand states into three sets:

- $\mathscr{H}$ : outcomes where it is optimal to have a finite contract term and therefore no subsidies,

- $\mathscr{L}$ : outcomes where subsidies are called for and therefore the contract lasts indefinitely,

- $\mathscr{I}$ : outcomes where the contract lasts indefinitely but no subsidies are involved.

With the notation introduced in section 5.2, let:

$$
G(\nu, \epsilon)=u^{\prime}(\nu-I)[\mu+\tau \ell(\nu, \varepsilon)] .
$$

The first order conditions (30a)-(30b) and $u^{\prime \prime}<0$ imply that

$$
\begin{aligned}
\mathscr{H} & =\{v: \mathscr{G}(\nu, \epsilon)<1+\lambda-\alpha\}, \\
\mathscr{I} & =\{v: 1+\lambda-\alpha \leq \mathscr{G}(\nu, \epsilon) \leq(1+\lambda)(1+\zeta)-\alpha\}, \\
\mathscr{L} & =\{v: \mathscr{G}(\nu, \epsilon)>(1+\lambda)(1+\zeta)-\alpha\},
\end{aligned}
$$


where $\epsilon$ is set equal to the value that maximizes the planner's objective function, which is assumed positive.

We want to show that there exist constants $m$ and $M$, with $m<M$, such that $\mathscr{H}, \mathscr{I}$ and $\mathscr{L}$ are characterized by $v>M, m \leq v \leq M$ and $v<m$, respectively. ${ }^{73}$ When $\ell \equiv 0$ in (49), this follows directly from $u^{\prime \prime}<0$. Yet once effort matters, we must show that, for all feasible values of $\epsilon, \mathscr{G}(\nu, \epsilon)$ crosses the horizontal lines $(1+\lambda)(1+\zeta)-\alpha$ and $1+\lambda-\alpha$ only once and from above ('single-crossing property'). The problem is not trivial because $\mu$ and $\tau$ are multipliers that vary with the problem's parameters and, in principle, can take any positive values.

\section{A particular case}

In what follows we assume that the distribution of users' willingness to pay follows an exponential distribution with mean $\theta$ that increases with effort $\epsilon$. The concessionaire has constant absolute risk aversion $A$. In the remainder of this appendix we find conditions on $\theta, k$ and $A$ so that the optimal contract derived in section 5.2 is of the two threshold type.

The distribution of discounted demand follows an exponential distribution with mean $\theta(\epsilon)$, with $\theta^{\prime}(\epsilon)>0$ :

$$
f(\nu \mid \epsilon)=\frac{1}{\theta} e^{-v / \theta} .
$$

It follows that:

$$
\ell(\nu, \epsilon)=\frac{\theta^{\prime}}{\theta}\left[\frac{v}{\theta}-1\right]
$$

and therefore

$$
\frac{\partial \ell(\nu, \epsilon)}{\partial v}=\frac{\theta^{\prime}}{\theta^{2}}>0
$$

and the MLRP holds.

Since the concessionaire has constant risk aversion, denoted by $A$ in what follows, the concessionaire's participation and incentive compatibility constraints lead to:

$$
\begin{aligned}
\int u^{\prime}(T(v)-I) f(\nu \mid \epsilon) d v & =1-k A \epsilon, \\
\int u^{\prime}(T(\nu)-I) \ell(\nu, \epsilon) f(\nu \mid \epsilon) d v & =-k A
\end{aligned}
$$

\section{A useful identity}

The first order conditions (28) and (29) imply that for all $v$ we have:

$$
1+\lambda-\alpha \leq u^{\prime}(T(\nu)-I)[\mu+\tau \ell(\nu, \epsilon)] \leq(1+\lambda)(1+\zeta)-\alpha .
$$

\footnotetext{
${ }^{73}$ Since we do not know the value of $\epsilon$ a priori, this must hold for all feasible values of $\epsilon$.
} 
Integrating over $v$ we then have:

$$
\mu \int u^{\prime}(T(v)-I) f(v \mid \epsilon) d v+\tau \int u^{\prime}(T(v)-I) \ell(\nu, \epsilon) f(\nu \mid \epsilon) d v=C,
$$

with $1+\lambda-\alpha \leq C \leq(1+\lambda)(1+\zeta)-\alpha$. Substituting (50) and (51) in this expression leads to:

$$
(1-k A \epsilon) \mu=\tau k A+C .
$$

Since $\mu, \tau$ and $C$ are positive, this expression implies that

$$
\epsilon<\frac{1}{k A} \text {. }
$$

Thus, as expected, optimal effort is smaller when the concessionaire is more risk averse or the cost of effort is higher. It also follows from (52) that:

$$
\frac{\mu}{\tau}=\frac{k A}{1-k A \epsilon}+\frac{C}{\tau(1-k A \epsilon)},
$$

and since $k A \epsilon<1$ and $C>0$, this implies that:

$$
\frac{\mu}{\tau}>k A .
$$

\section{Sufficient condition}

A straightforward calculation shows that:

$$
\frac{\partial \mathscr{G}}{\partial \epsilon}(\nu, \epsilon)=-e^{-A(\nu-I)}\left[A \mu-\tau \frac{\theta^{\prime}}{\theta^{2}}(1+A \theta)+A \tau \frac{\theta^{\prime}}{\theta^{2}} \nu\right] .
$$

It follows that $\mathscr{G}(\nu, \epsilon)$ is decreasing in $v$ over the entire range of possible values if and only if

$$
A \mu>\tau \frac{\theta^{\prime}}{\theta^{2}}(1+A \theta)
$$

that is, if and only if

$$
\frac{\mu}{\tau}>\frac{\theta^{\prime}}{\theta}\left(1+\frac{1}{A \theta}\right)
$$

From (53) and (54) it follows that

$$
k A>\frac{\theta^{\prime}}{\theta}\left(1+\frac{1}{A \theta}\right)
$$

is sufficient to ensure that the optimal policy is of the two-threshold type. 